\title{
Chemical assessment of the explosive chamber in the projector system of Hayabusa2 for asteroid sampling
}

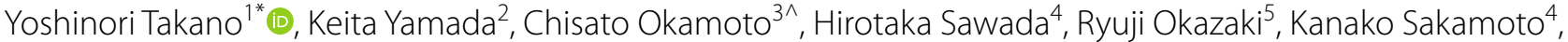 \\ Yoko Kebukawa ${ }^{6}$ (D), Kento Kiryu ${ }^{6}$, Takazo Shibuya ${ }^{7}$, Motoko Igisu ${ }^{7}$, Hajime Yano ${ }^{4}$, Shogo Tachibana ${ }^{4,8}$ (D) \\ and Hayabusa2 project team ${ }^{4}$
}

\begin{abstract}
We report a chemical assessment of the explosive chamber in the projector system used during the sampling operation of the Hayabusa2 project at the surface of the C-type asteroid Ryugu. Although the explosion process was designed as a closed system, volatile combustion gases and semivolatile organics were produced together with quenched carbonaceous product. The chemical compositions of the gases, organics, and inorganics were investigated in the screening analysis. A solid-phase microextraction technique and thermal desorption coupled with gas chromatography/mass spectrometry analysis revealed that aliphatic $\left(<C_{20} n\right.$-alkanes) and aromatic ( $<$ pyrene) hydrocarbons were produced in the closed chamber system. The aromatic ring compositions of the latter showed a semilogarithmic decrease: one ring $>$ two rings $>$ three rings $>$ four rings, resulting in abiogenic molecular patterns. The most intense inorganic fingerprints were due to potassium $\left(\mathrm{K}^{+}\right)$and chloride $\left(\mathrm{Cl}^{-}\right)$ions derived from the initial KTB explosive and RK ignition charge. We discuss quality control and quality assurance issues applicable to future sample processes during the Hayabusa2 project.
\end{abstract}

Keywords: Abiogenic organic molecules, Aliphatic and aromatic hydrocarbons, Explosion products, Nominal and off-nominal assessment, Energetic reaction with quenching effect

\section{Introduction}

Hayabusa2 is a sample-and-return mission to the C-type asteroid (162173) Ryugu to achieve a comprehensive understanding of the evolutionary history of the solar system (e.g., Tachibana et al. 2014). The Hayabusa2 spacecraft found that Ryugu is a dark rubble pile body, and hydrated silicates are ubiquitous on its surface (Watanabe et al. 2019; Kitazato et al. 2019; Sugita et al. 2019). The spacecraft successfully performed two sampling operations on the Ryugu surface materials, which

\footnotetext{
*Correspondence: takano@jamstec.go.jp

${ }^{1}$ Biogeochemistry Research Center (BGC), Japan Agency for Marine-Earth Science and Technology (JAMSTEC), Natsushima, Yokosuka 237-0061, Japan

Full list of author information is available at the end of the article Chisato Okamoto-Deceased
}

will be returned to Earth in late 2020. The basic concept of the Hayabusa2 sampling system has been described previously (e.g., Tachibana et al. 2014; Sawada et al. 2017; Okazaki et al. 2017). To collect enough sample ( 100 mg) from the Ryugu surface, each $5 \mathrm{~g}$ of tantalum (Ta) projectile was used at the time of touch-down during the sampling operation (Sawada et al. 2017). The projectile shooting operation has three steps: (1) explosion in the explosive chamber; (2) acceleration of the projectile by the combustion gas within the closed sabot system; and (3) projectile shooting at $300 \mathrm{~m} \mathrm{~s}^{-1}$ after separation from the sabot using combustion gas stored in the explosive chamber (Fig. 1). To date, the chemical properties of the explosive products, including deflagration and detonation processes, have been investigated mainly in terms of the formation of solid materials, including amorphous 


\section{a}
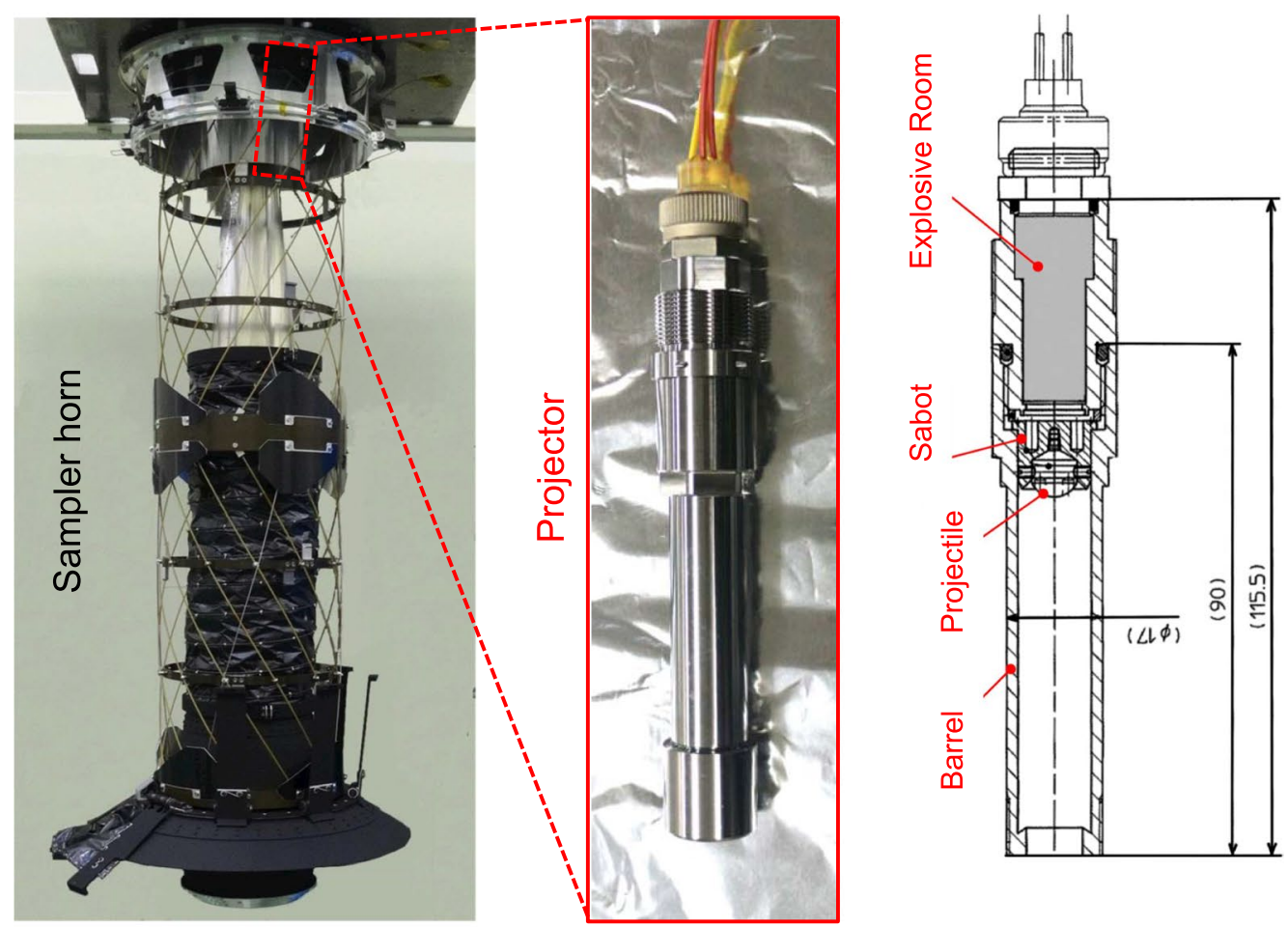

b

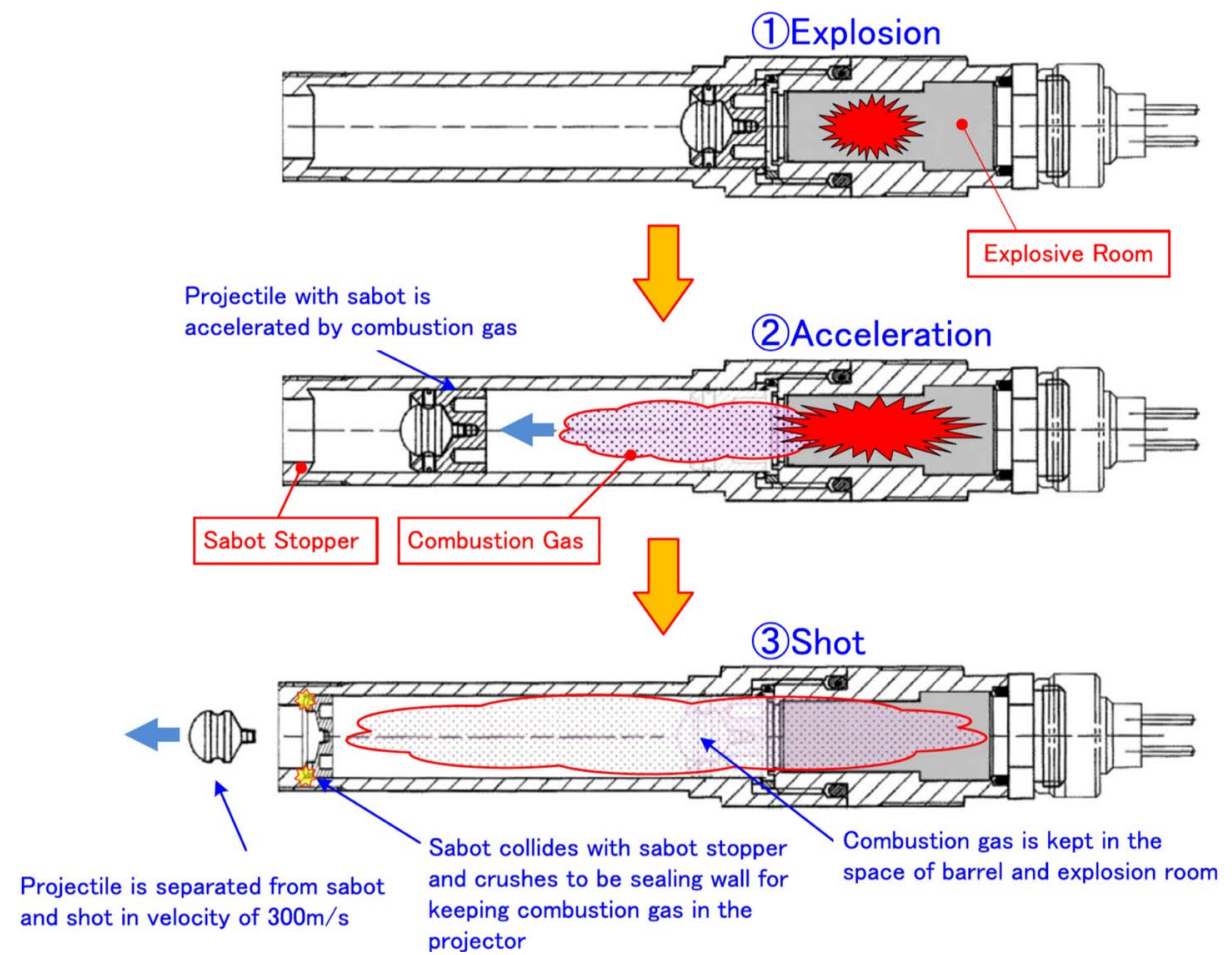

Fig. 1 a Photograph of the Hayabusa2 sampler horn (Tachibana et al. 2014) and projector system with a schematic diagram showing the structure of the barrel, projectile, sabot, and explosive chamber (Sawada et al. 2017). b Schematic representation of the shooting operation of the projector system showing (1) the explosion, (2) acceleration, and (3) shot of the projectile 
carbon composites, shocked graphite, and occasionally diamond (e.g., Greiner et al. 1988; Titov et al. 1989; Kuznetsov et al. 1994; Chen et al. 2003; Mansurov 2005).

Here, we note that the explosion for projectile shooting occurs in the closed system inside the projector during the nominal operation case (Sawada et al. 2017) and that the explosive products that we report in this study are not considered to be mixed with the returned sample except in the off-nominal case, where the leakage of explosive products occurs from the projector. We also note that we have previously studied the analytical pathways in Hayabusa based on an investigation of category 3 carbonaceous particles, which indicated analogous potential contaminants that could be observed throughout the sampling processes of Hayabusa2 (e.g., Ito et al. 2014; Yabuta et al. 2014; Uesugi et al. 2014; Naraoka et al. 2015; Kitajima et al. 2015). To exclude the potential artifact of any carbonaceous materials, categorizing the sample grain is one of rational ways in regard to quality control and quality assurance, likewise the procedure of Itokawa-returned sample in the Hayabusa mission (e.g., Uesugi et al. 2019).

The explosive products for projectile shooting are potential contaminants of Hayabusa2-returned Ryugu samples. However, the chemical compositions and functional groups of the volatile and nonvolatile organic compounds preserved in the carbonaceous product are largely unknown, including those of labile organic compounds. In this study, we assessed the projector system in terms of the chemical composition of the volatile gases and nonvolatile organic compounds in a laboratorybased simulation experiment, which should provide useful information on contaminants for curation and analysis of the returned samples.

\section{Assessment procedure}

Explosion experiments in the closed system

The Hayabusa (MUSES-C) impact sampling system (i.e., "sampler") including the projector sub-system was originally designed and developed by Yano et al. (2002), Fujiwara and Yano (2005), and Yano et al. (2006). The Hayabusa2's sampling system added minor modification from the Hayabusa sampler while its projector sub-system kept its original design, which was jointly developed by ISAS, Tohoku University and Nichiyu Giken, Co, Ltd.

To simulate the explosive chamber in the projector (Tachibana et al. 2014), we performed an experiment using identical components (i.e., equivalent to the flight model; Sawada et al. 2017) for the KTB explosive $\left(\mathrm{KClO}_{4}\right.$, 69.5\%; $\mathrm{TiH}_{2}, 19.5 \%$; B, 9.5\%; and nitrocellulose, 1.5\%) with an RK ignition charge $\left[\mathrm{Pb}(\mathrm{SCN})_{2}, \sim 50 \%\right.$; $\mathrm{KClO}_{3}, \sim 50 \%$; and nitrocellulose, $\leq 1 \%$; the chemical formula is shown in Fig. 2] under ambient temperature and low pressure ( $<40 \mathrm{~Pa}$, with Ar gas evacuated). Figure 3 shows the configuration of the experimental explosion chamber at the Institute of Space and Astronautical Science (ISAS), Sagamihara, Japan.

The schematic illustration (Fig. 3f) shows the projectile chamber, explosive chamber, and sample port for gas cylinders. After the explosion in the closed chamber, a gas sample was collected, together with quenched solid samples and relic materials (Fig. 4). We conducted the simulation with and without the sabot equipment for the purpose of nominal and off-nominal verification. All glassware used in the assessment were cleaned

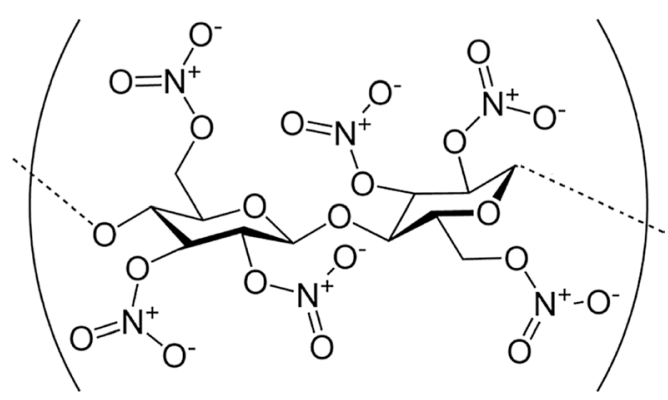

Nitrocellulose

Chemical Formula: $\left[\mathrm{C}_{6} \mathrm{H}_{7}\left(\mathrm{NO}_{2}\right)_{3} \mathrm{O}_{5}\right] n$<smiles>N#C[S-]</smiles>

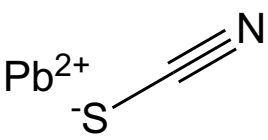

Lead (II) thiocyanate

Chemical Formula: $\mathrm{Pb}(\mathrm{SCN})_{2}$

Exact Mass: 323.93

Molecular Weight: 323.36

Flash point: $4.4^{\circ} \mathrm{C}$

Fig. 2 Chemical structure of the nitrocellulose and lead(II) thiocyanate in the KTB and RK ignition charge explosives 

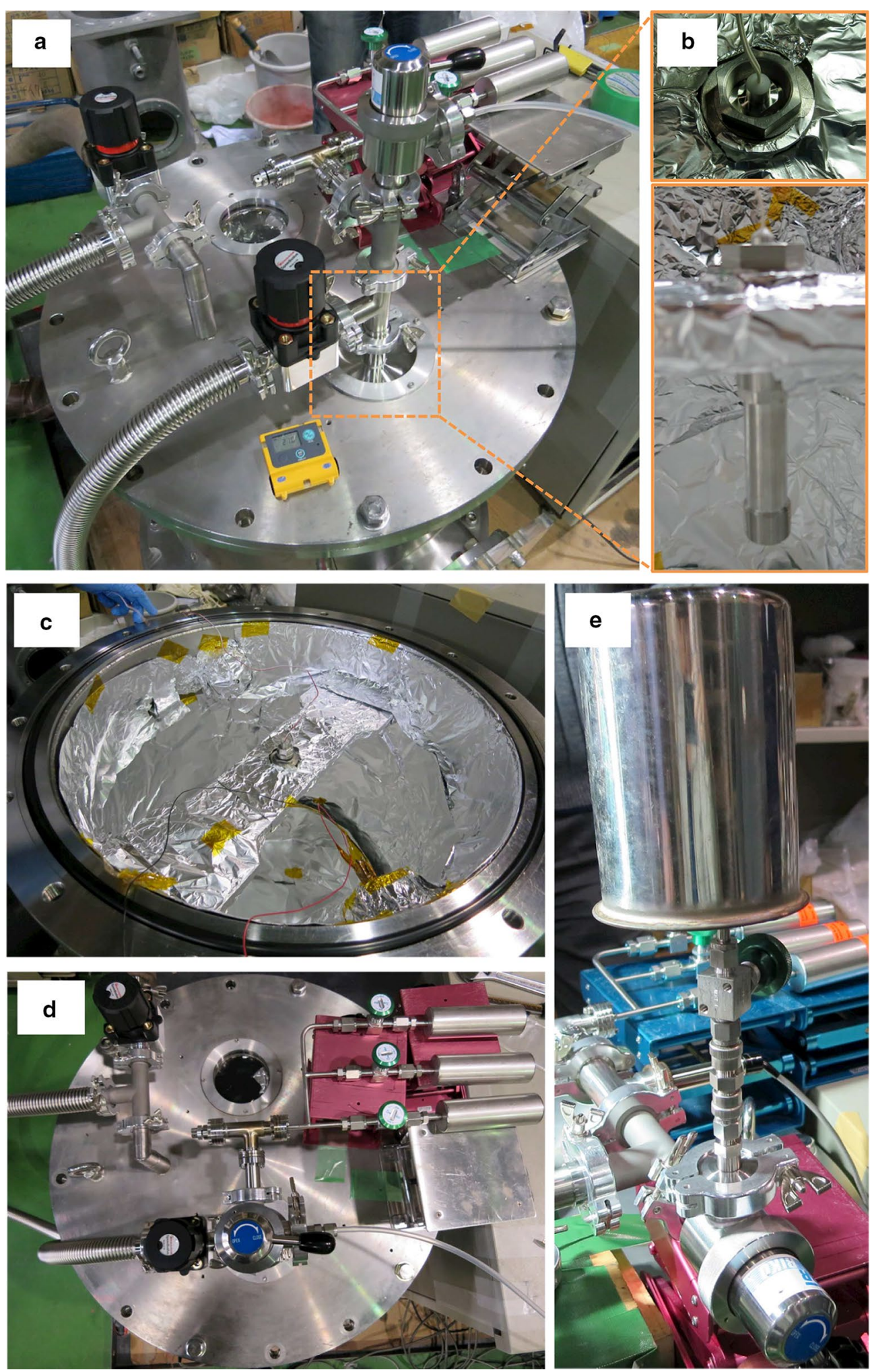

Fig. 3 Apparatus and configuration of the laboratory-based projector system at the Institute of Space and Astronautical Science (ISAS), Sagamihara, in March 2015; a upper part of the projectile chamber, $\mathbf{b}$ explosive chamber, $\mathbf{c}$ interior of the projectile chamber, $\mathbf{d}$, e gas sample cylinders, and $\mathbf{f}$ schematic diagram of the entire simulation. The anomalous element profiles of metal (e.g., Aluminum) derived from the explosive chamber are potential indicators to trace the artifact if the sample has affected by off-nominal projectile operation 


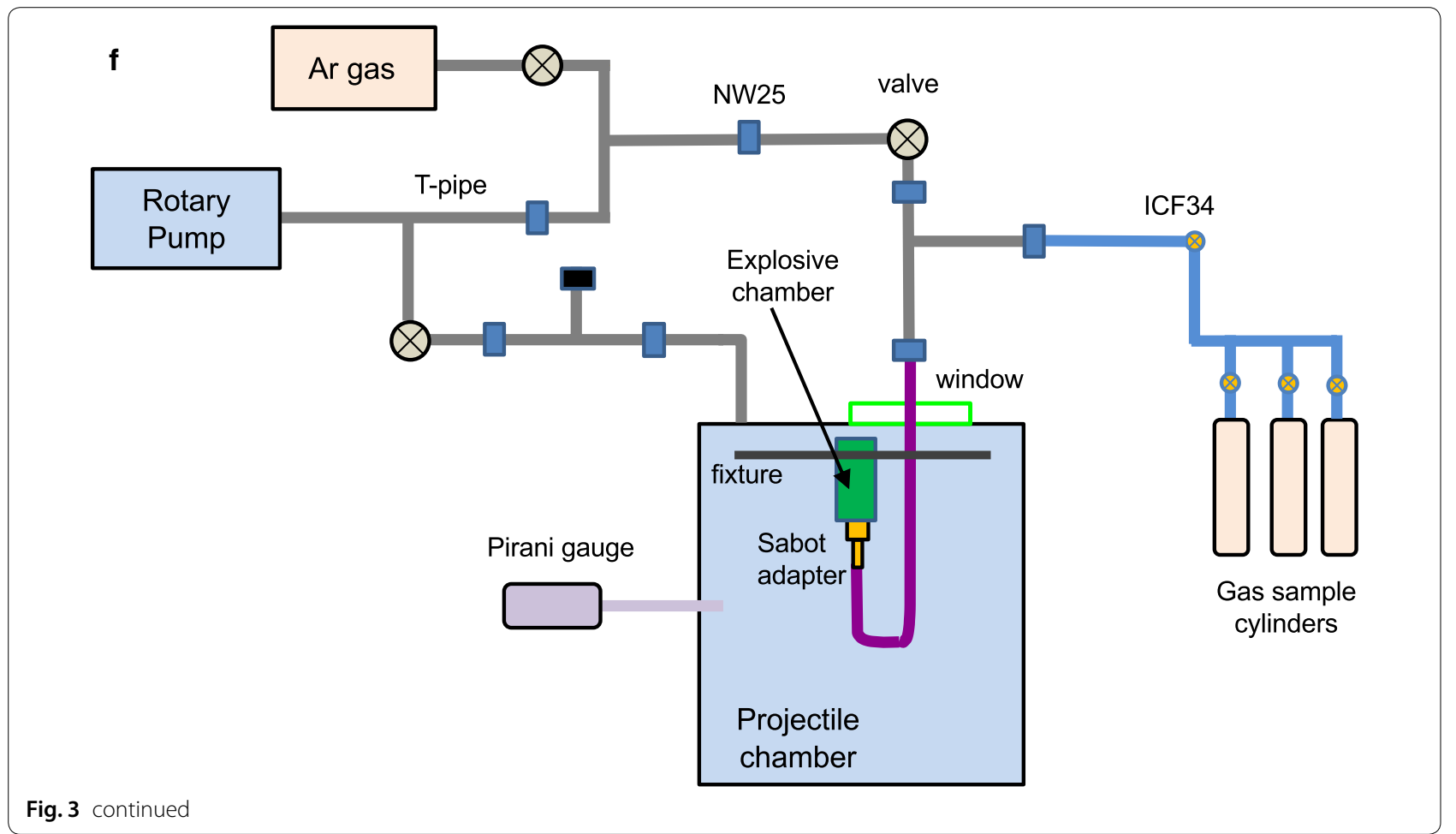

beforehand by heating at $450{ }^{\circ} \mathrm{C}$ for $5 \mathrm{~h}$ in air to remove any artifact materials of organic contaminants.

\section{Analysis of the volatile gas molecules by SPME-GC/MS}

The volatile organic compounds (VOCs) contained in the gas sample were analyzed by gas chromatography/mass spectrometry (GC/MS). The gas sample was injected into the GC/MS system using a gastight syringe following solid-phase microextraction (SPME) (Arthur and Pawliszyn 1990), and these techniques have been successfully applied in a wide variety of fields (e.g., Ligor et al. 2007; Wang and Lu 2009; Szmigielski et al. 2012; Tuckey et al. 2013; García et al. 2014). In brief, SPME was conducted with an $85-\mu \mathrm{m}$ fiber coated with carboxen-polydimethylsiloxane (Carboxen ${ }^{\mathrm{TM}}-\mathrm{PDMS}$ StableFlex ${ }^{\mathrm{TM}}$; Supelco; PA, USA). The VOCs were extracted for $60 \mathrm{~min}$ at $60^{\circ} \mathrm{C}$, after which the fiber was transferred to the injection port of the GC-MS system (Agilent 5975C GC/MSD, Agilent Technologies, Inc.), which was maintained at $240{ }^{\circ} \mathrm{C}$ for $5 \mathrm{~min}$, and the sample was injected in splitless mode. A capillary column (CP-PoraBOND Q, $25 \mathrm{~m} \times 0.32 \mathrm{~mm}$ i.d.; $5 \mu \mathrm{m}$ film thickness; Varian, CA, USA) was used for chromatographic separations. The GC oven was kept at $35^{\circ} \mathrm{C}$ for $5 \mathrm{~min}$ and then ramped up at $15^{\circ} \mathrm{C} \mathrm{min}^{-1}$ to $120^{\circ} \mathrm{C}$ for $10 \mathrm{~min}$ before ramping at $50{ }^{\circ} \mathrm{C} \mathrm{min}^{-1}$ to $200{ }^{\circ} \mathrm{C}$ for $6 \mathrm{~min}$. The helium carrier gas flow rate was $1.5 \mathrm{~mL} \mathrm{~min}^{-1}$ in constant flow mode. The quadrupole MS system was operated in electron ionization mode with a scan range of $m / z=10-500$. To avoid memory effects, the SPME fiber was conditioned at $250{ }^{\circ} \mathrm{C}$ for $10 \mathrm{~min}$ before each measurement. Compounds were identified by comparison with data in the mass spectral library (Wiley Registry of Mass Spectral Data, 7th edition) included with MSD ChemStation software (Agilent Technologies, Inc.).

\section{Analysis of the semivolatile molecules by TD-GC/MS}

The semivolatile compounds were analyzed by online thermal desorption (TD)-GC/MS using a multipurpose sampling and thermal desorption system (MSTD-258M; GL Science Inc.) and a purge and trap device (P\&T; Gestel TDS A2, Gestel Inc.) coupled to a GC/MS system (Agilent $6890 \mathrm{~N}$ and 5973 MSD; Agilent Technologies Inc.). The MSTD sampling chamber was a quartz vessel $90 \mathrm{~mm}$ in diameter and $40 \mathrm{~mm}$ in height. The thermal desorption program was as follows. The chamber was purged with $\mathrm{N}_{2}$ at $340 \mathrm{~mL} \mathrm{~min}{ }^{-1}$ for 1 min at $280{ }^{\circ} \mathrm{C}$. The trapping time was $30 \mathrm{~min}$ with an $\mathrm{N}_{2}$ flow rate of $150 \mathrm{~mL} \mathrm{~min}^{-1}$. The out-gas cold trap was maintained at temperatures below $-100{ }^{\circ} \mathrm{C}$ in the TDS unit. A DB-5MS capillary column $(30 \mathrm{~m} \times 0.25 \mathrm{~mm}$ i.d.; 0.52 $\mu \mathrm{m}$ film thickness; Agilent Technologies Inc.) was used for chromatographic separations, and MS compound detection was achieved in electron impact mode. The GC oven temperature was programmed as follows: initial temperature of $40{ }^{\circ} \mathrm{C}$ for $3 \mathrm{~min}$; ramped up at $9{ }^{\circ} \mathrm{C}$ 

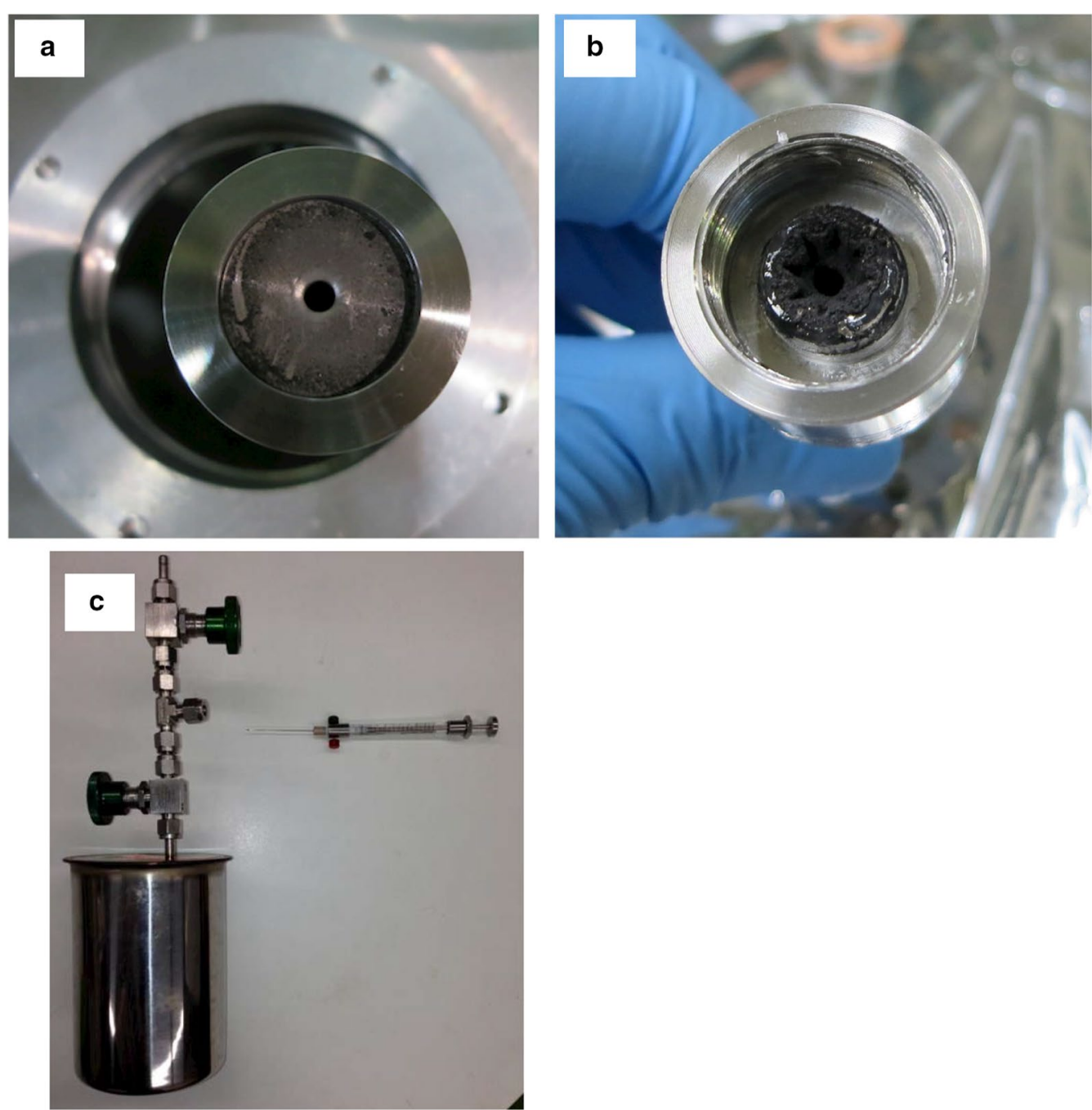

Fig. 4 a, b Carbonaceous product after the explosion simulation. c Volatile gas sample cylinder

$\min ^{-1}$ to $220{ }^{\circ} \mathrm{C}$, then at $10{ }^{\circ} \mathrm{C} \min ^{-1}$ to $280{ }^{\circ} \mathrm{C}$ where it was maintained for $5 \mathrm{~min}$. The He carrier gas flow rate

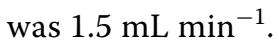

\section{Analysis of the inorganic ions and elements in solid carbonaceous product}

The analyses of inorganic water-soluble cations and anions involved ion chromatography (IC; DX-120 for cations; DX-500 for anions; Dionex Inc.) with Ion Pac CS10 and Ion Pac AS17 columns for cations and anions, respectively (Dionex Inc.). Gradient elution was conducted with three solvents: $25 \mathrm{mM}$ methanesulfonic acid, 1.2 M methanol, and $0.95 \mathrm{M}$ acetonitrile at a flow rate of $1.0 \mathrm{~mL} \mathrm{~min}^{-1}$ for cations and $\mathrm{H}_{2} \mathrm{O}, 5 \mathrm{mM} \mathrm{NaOH}$, and $100 \mathrm{mM} \mathrm{NaOH}$ at a flow rate of $1.5 \mathrm{~mL} \mathrm{~min}^{-1}$ for anions. For metal elemental analyses, inductively coupled plasma-mass spectrometry (ICP-MS; 7500 s, Agilent
Technologies. Inc) was used for environmental assessment. For further profiling of the solid product, we also performed qualitative micro-X-ray fluorescence analysis $(\mu \mathrm{XRF})$ of the carbonaceous product using an XGT$5000 \mathrm{~S}$ system (Horiba Ltd.) with a resolution of $10 \mu \mathrm{m}$ for surface imaging.

\section{Fourier transform infrared spectroscopy}

As a nondestructive spectroscopic technique, we performed Fourier transform infrared (FT-IR) spectroscopy following the procedure described in Kebukawa et al. (2020). Infrared absorption spectra were collected from a small amount of sample pressed onto a $\mathrm{KBr}$ plate $\left(\sim 5 \times 5 \times 1 \mathrm{~mm}^{3}\right)$ using a micro-FT-IR instrument (JASCO FT/IR-6100 + IRT-5200) equipped with a ceramic IR light source, a germanium-coated $\mathrm{KBr}$ beam splitter, a mercury-cadmium-telluride (MCT) detector, and $\times 16$ 
Cassegrainian mirrors. A total of 128 scans of the IR transmission were accumulated with a wavenumber resolution of $8 \mathrm{~cm}^{-1}$ in the wavenumber range of $4000-700 \mathrm{~cm}^{-1}$ and with a $50 \times 50 \mu \mathrm{m}^{2}$ aperture for each spectrum. Background spectra were acquired from the blank areas of the $\mathrm{KBr}$ plate adjacent to the samples.

\section{Raman spectroscopy}

A sample was directly analyzed by an established method (after Kiryu et al. 2019) using a Raman spectrometer (Nanophoton RAMAN touch). In brief, a 532-nm laser was used, and the laser beam was focused through a $\times 20$ objective. The spot size was $\sim 1 \mu \mathrm{m}(\times 20$ objective with a numerical aperture of 0.45 ), and the laser power at the sample surface was $\sim 700 \mu \mathrm{W}$. The spectral range was $100-2600 \mathrm{~cm}^{-1}$, and a grating of 600 grooves $\mathrm{mm}^{-1}$ was used. The exposure time for each spectrum was $20 \mathrm{~s}$, and two accumulations were obtained for each analytical spot to correct for cosmic rays. The Raman shift was calibrated using a silicon wafer prior to the analytical procedure.

\section{Results and discussion}

Volatile and semivolatile molecules from the explosion

The VOCs detected in the projectile chamber included $\mathrm{CH}_{4}\left[19.8 \mu \mathrm{mol}\right.$ carbon $\left.(\mu \mathrm{mol} \mathrm{C}) \mathrm{L}^{-1}\right], \mathrm{C}_{2} \mathrm{H}_{4}(0.9 \mu \mathrm{mol}$ $\left.\mathrm{C} \mathrm{L}^{-1}\right), \mathrm{C}_{2} \mathrm{H}_{6}\left(0.6 \mu \mathrm{mol} \mathrm{C} \mathrm{L}{ }^{-1}\right)$, and benzene $(0.4 \mu \mathrm{mol} \mathrm{C}$ $\left.\mathrm{L}^{-1}\right)$ (Fig. 5). The methane/ethane ratio $\left(\mathrm{C}_{1} / \mathrm{C}_{2}\right)$ was 33.0, which is unlike the value of 1.04 found for the Murchison meteorite (methane, $8.9 \mathrm{nmol} \mathrm{g}^{-1}$; ethane, $8.5 \mathrm{nmol} \mathrm{g}^{-1}$; data from Yuen et al. 1984). The low-molecular-weight carboxylic acids (including acetic acid) and various other organic molecules detected by total ion chromatogram (TIC) on the TD-GC/MS are shown in Fig. 6a. A wide range of aliphatic hydrocarbons, including straight chain alkanes $\left(<n-\mathrm{C}_{20} \mathrm{H}_{42}\right)$, were detected in the extracted ion chromatogram (EIC, $m / z=57$ ).

A number of polycyclic aromatic hydrocarbons (PAHs) and heterocyclic hydrocarbons were identified (Fig. 6bd), with the most abundant being benzene $(m / z=78)$ and toluene $(m / z=91$ and 92 with benzyl cation isomerism; Appendix), which is consistent with the results of volatile gas analysis by GC/MS. $\mathrm{C}_{2}$-Alkylbenzenes $(m / z=106)$, including ethyl benzene and xylene $\left(o_{-}^{-}, m^{-}\right.$, and $\left.p-\right)$, were also observed. Naphthalene $(m / z=128)$ was the

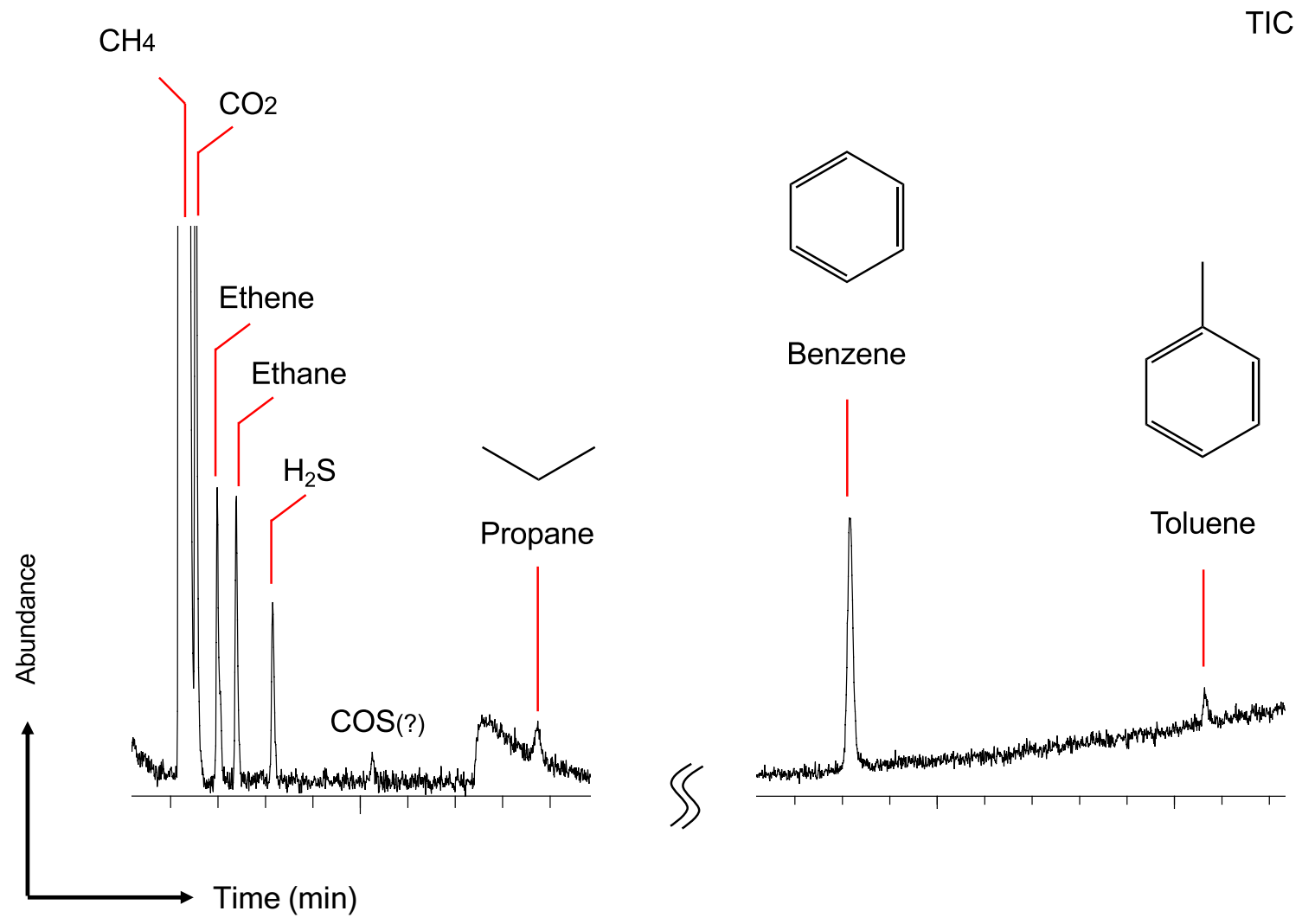

Fig. 5 GC/MS chromatograms showing the volatile gases (methane, carbon dioxide, ethene, ethane, hydrogen sulfide, propane, benzene, and toluene) from the quenched carbonaceous product (w/o sabot). T/C total ion chromatogram 
a) Aliphatic molecules

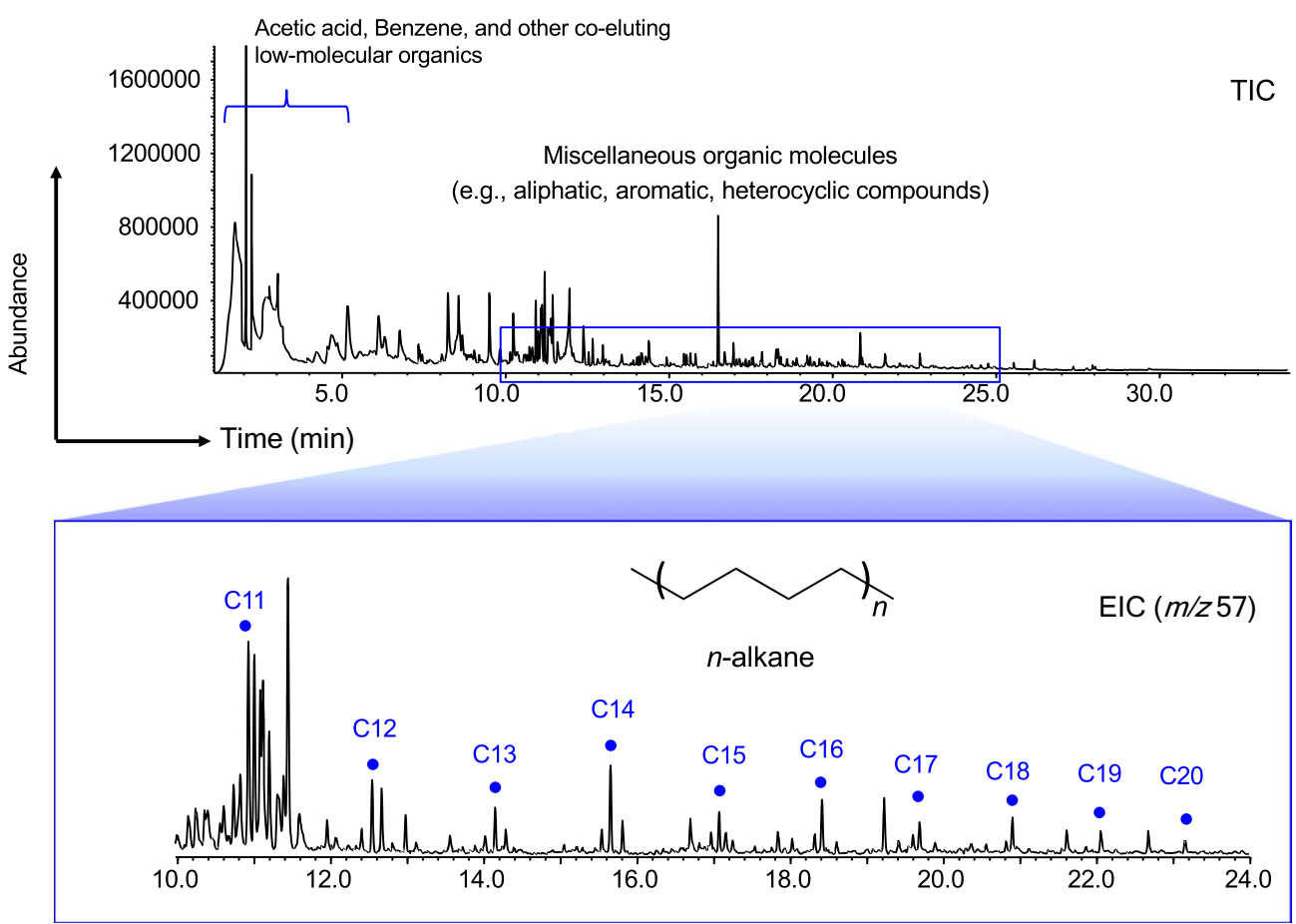

b) Aromatic molecules: 1-Rings

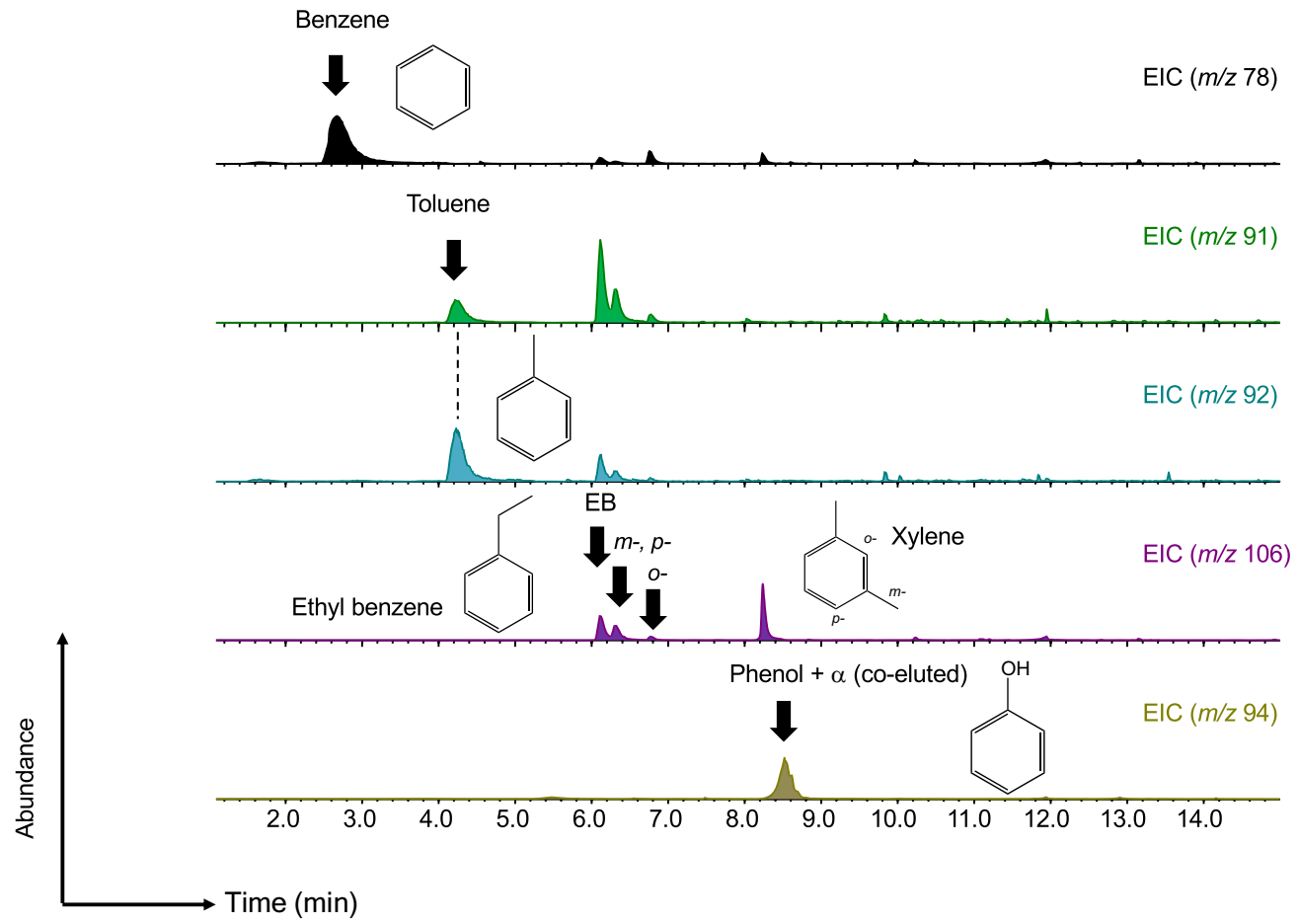

Fig. 6 TD-GC/MS chromatograms of a the aliphatic molecules ( $n$-alkanes); b-e aromatic molecules (e.g., monocyclic species: benzene, toluene, ethyl benzene, xylene, and phenol; bicyclic species: naphthalene, methyl naphthalene, dimethyl-naphthalene, and biphenyl; tricyclic species: phenanthrene, anthracene, methyl phenanthrene; and tetracyclic species: fluoranthene and pyrene); f heterocyclic molecules (e.g., dibenzofuran) from the quenched carbonaceous product without the sabot system (w/o sabot). Please see also Fig. 7 for a comparison of PAH profiles from the systems w/ or w/o the sabot 
c) Aromatic molecules: 2-Rings

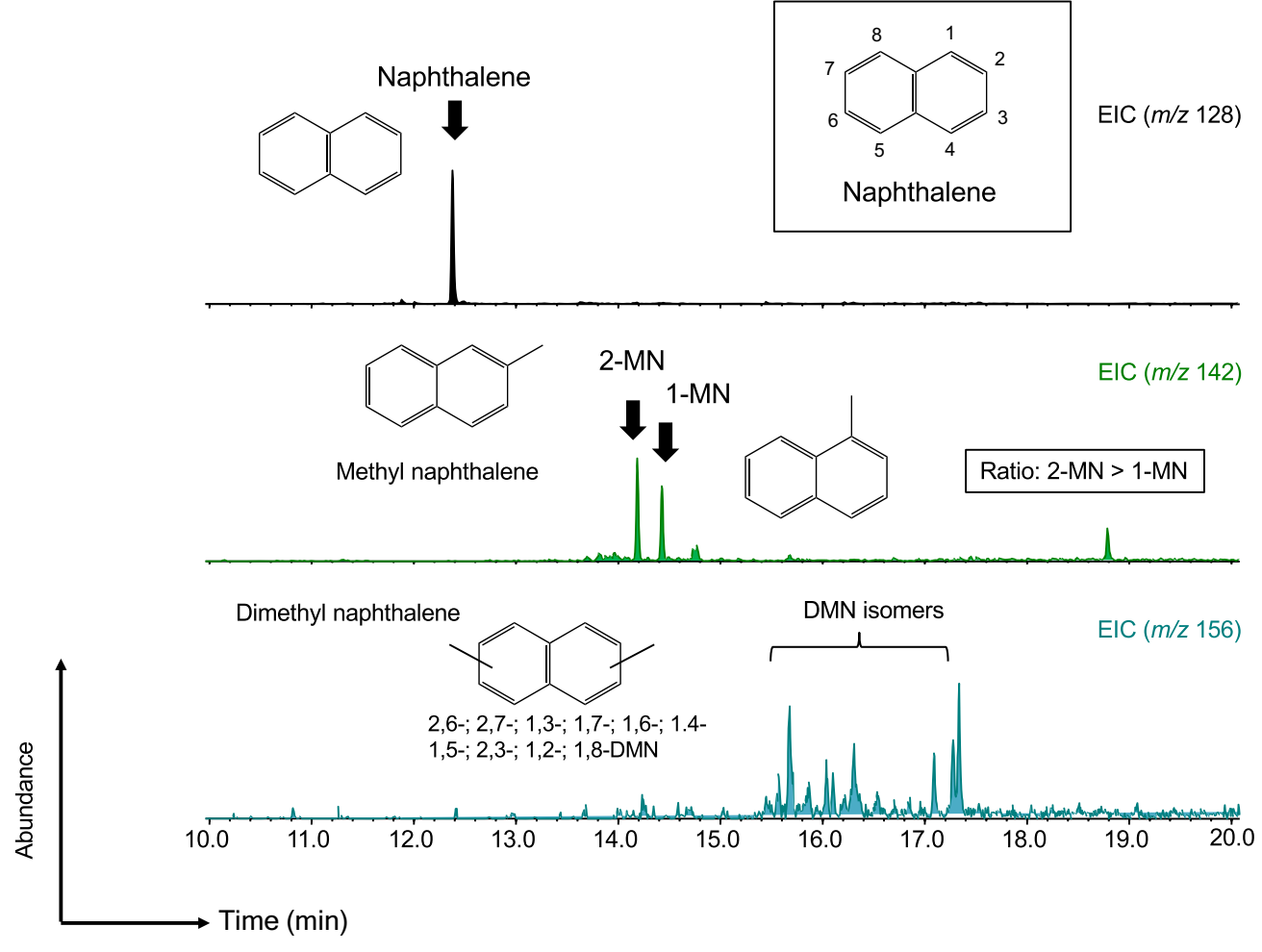

d) Aromatic molecules: 2,3-Rings

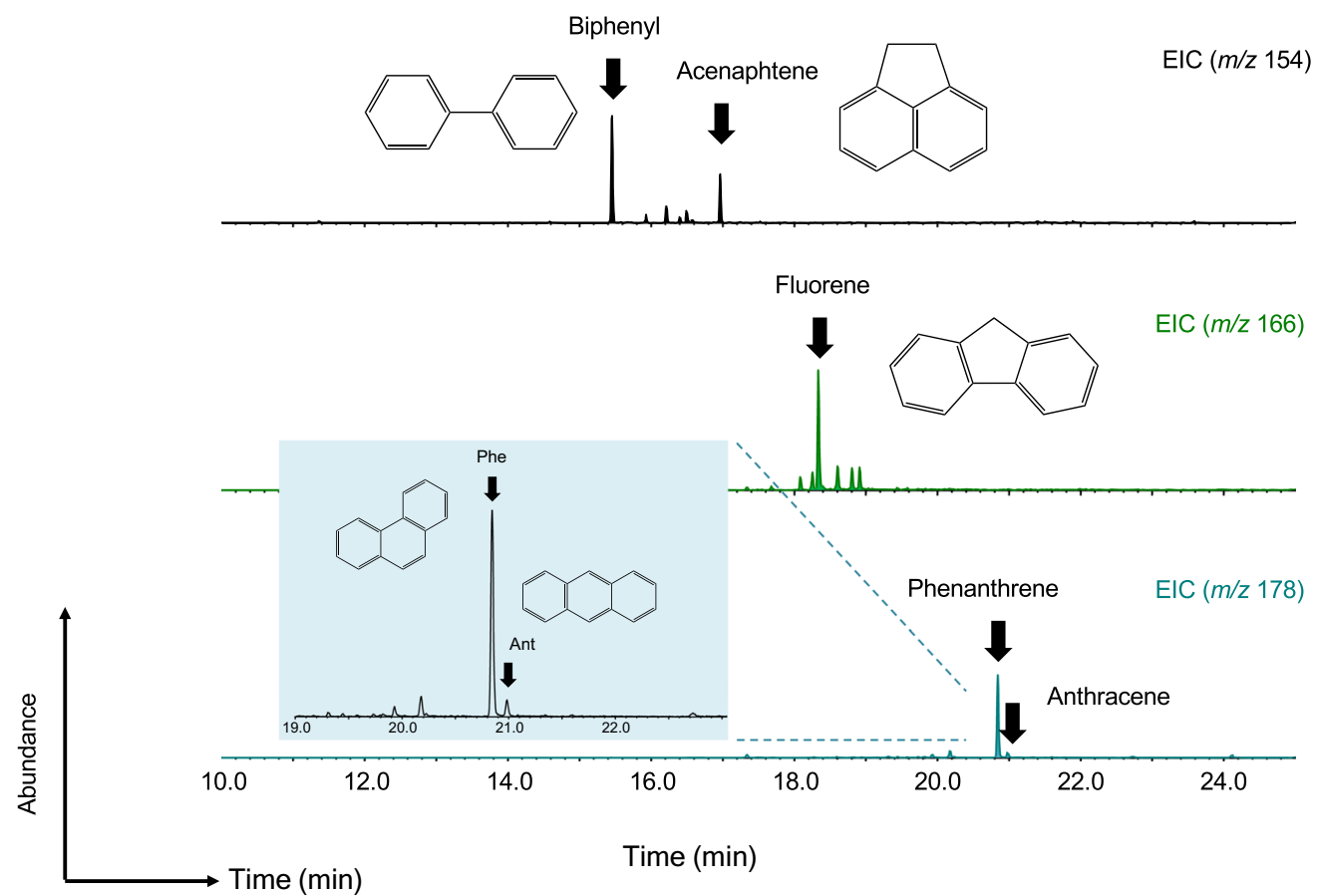

Fig. 6 continued 
e) Aromatic molecules: 3,4-Rings

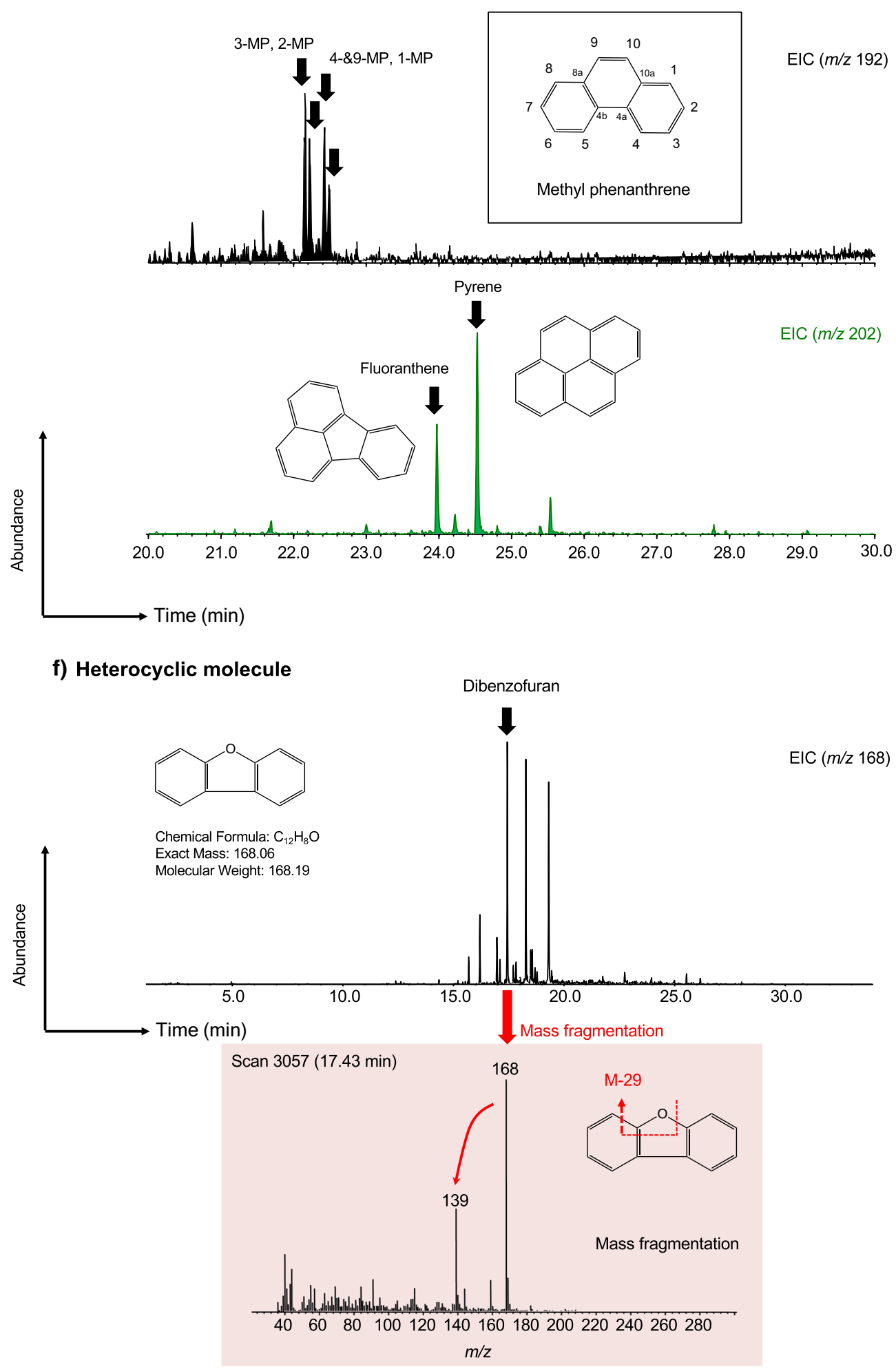

Fig. 6 continued 


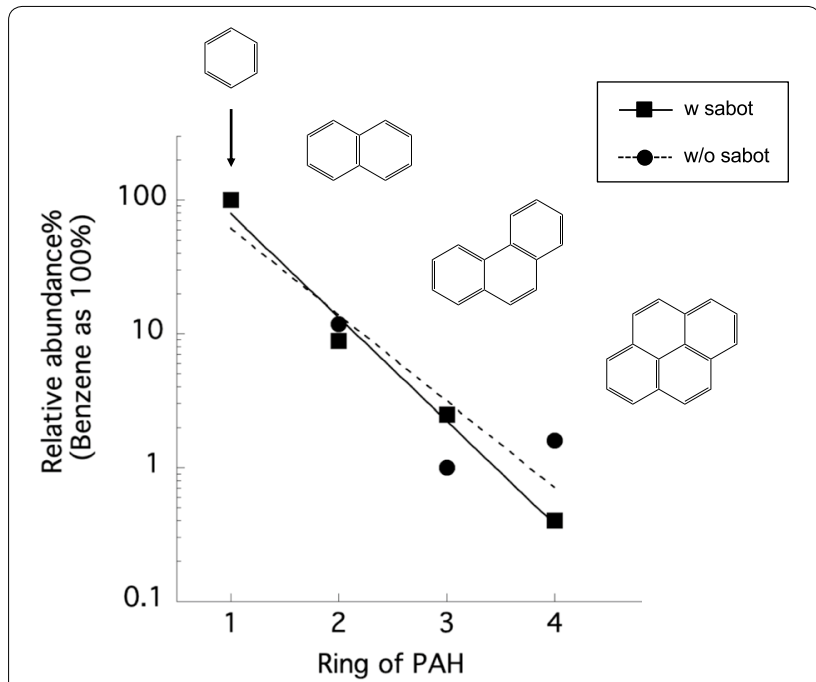

Fig. 7 The relationship between the number of rings of the PAHs and their relative abundance normalized to benzene at 100 . The abundance profiles were from benzene (monocyclic), naphthalene (bicyclic), phenanthrene (tricyclic), and pyrene (tetracyclic), where the concentrations of alkyl-PAHs were not included in the determination of each relative abundance. For further description of carbonaceous products, the detailed analysis of soluble organic matter using polar and apolar solvents will have to be performed by high-resolution mass spectrometry with appropriate wet-chemical treatments (e.g., Orbitrap mass spectrometry by Oba et al. 2019; Isotope ratio mass spectrometry by Takano et al. 2015) most abundant bicyclic species among the isomers of methyl- and dimethyl-naphthalene $(\mathrm{m} / \mathrm{z}=142$ and 156 , respectively). The experimentally derived ratios of methyl naphthalene isomers (2-methyl ( $\beta$-configured) to 1-methyl ( $\alpha$-configured) naphthalene) (Radke et al. 1982) obtained with and without the sabot device were 1.50 and 1.27 , respectively, which are similar to the ranges reported for carbonaceous meteorites (Yamato-790112, 2.02; Murchison, 1.86; Renazzo, 1.44; Pearson et al. 2006) and products of impact shock experiments of benzene (Mimura, 1995). Biphenyl $(m / z=154)$, acenaphthene $(m / z=154)$, fluorene $(m / z=166)$, and phenanthrene/ anthracene $(m / z=178)$ are also known as abiogenic bicyclic and tricyclic aromatics. The detection of tri- and tetracyclic aromatics and heterocyclic methyl phenanthrene $(m / z=192)$, fluoranthene/pyrene $(m / z=202)$, and dibenzofuran $(m / z=168)$ indicates that aromatic cyclization processes occurred in the explosion and quenching processes. The relative abundance of the aromatic compounds and their isomers decreases semilogarithmically with increasing chain length, i.e., 1 ring (benzene) $>2$ rings (naphthalene) $>3$ rings (phenanthrene) $>4$ rings (pyrene), in experiments both with and without the sabot device (Fig. 7). The semilogarithmic linear relations between PAHs (Xn: number of rings) and their relative abundance \% (Y; benzene as 100) are expressed as
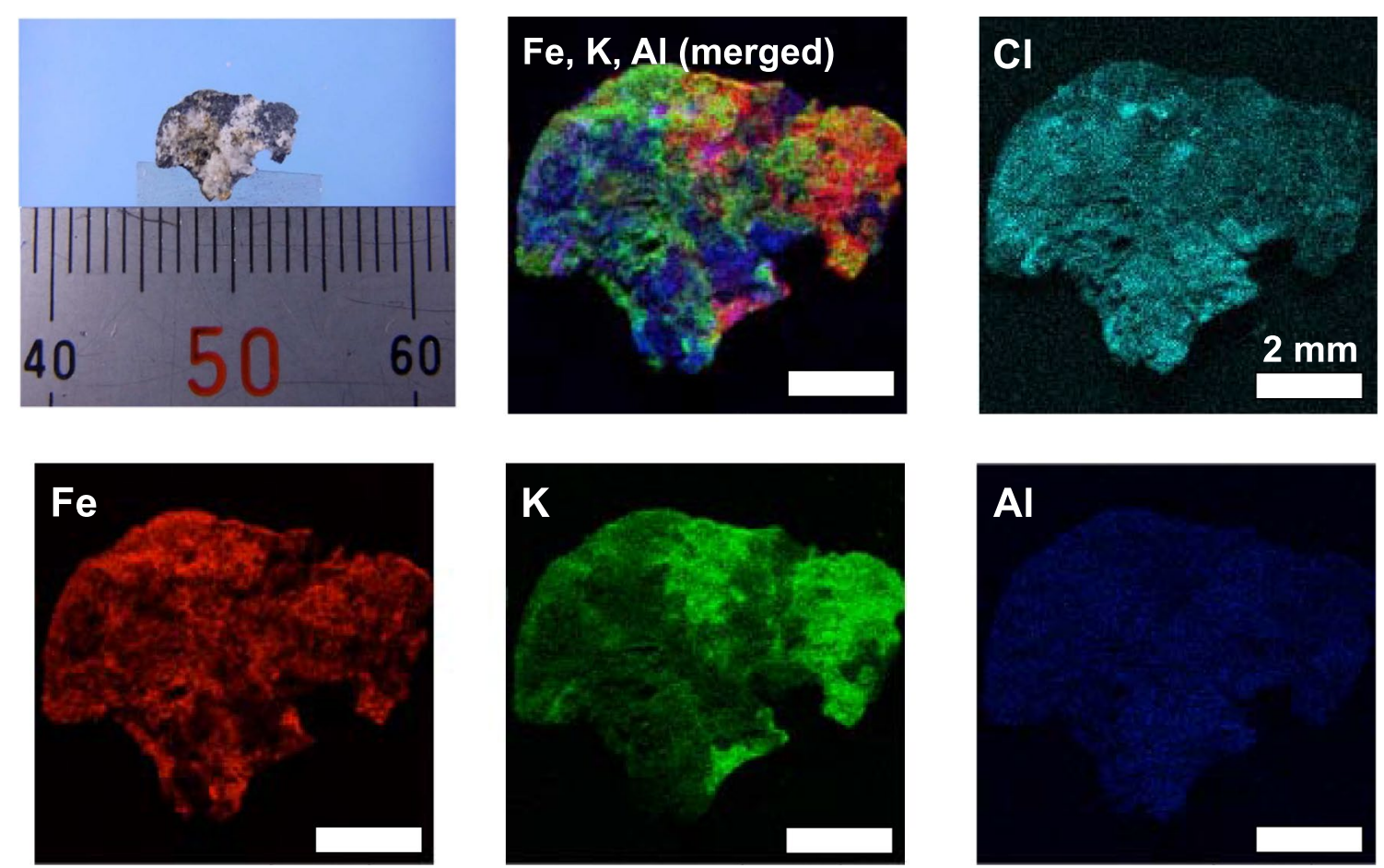

Fig. 8 UXRF surface imaging for representative elements ( $\mathrm{Fe}$, red; $\mathrm{K}$, green; $\mathrm{Al}$, blue; and $\mathrm{Cl}$, light blue) for the carbonaceous products (the explosion experiment with the sabot). The white scale bar represents $2 \mathrm{~mm}$ 

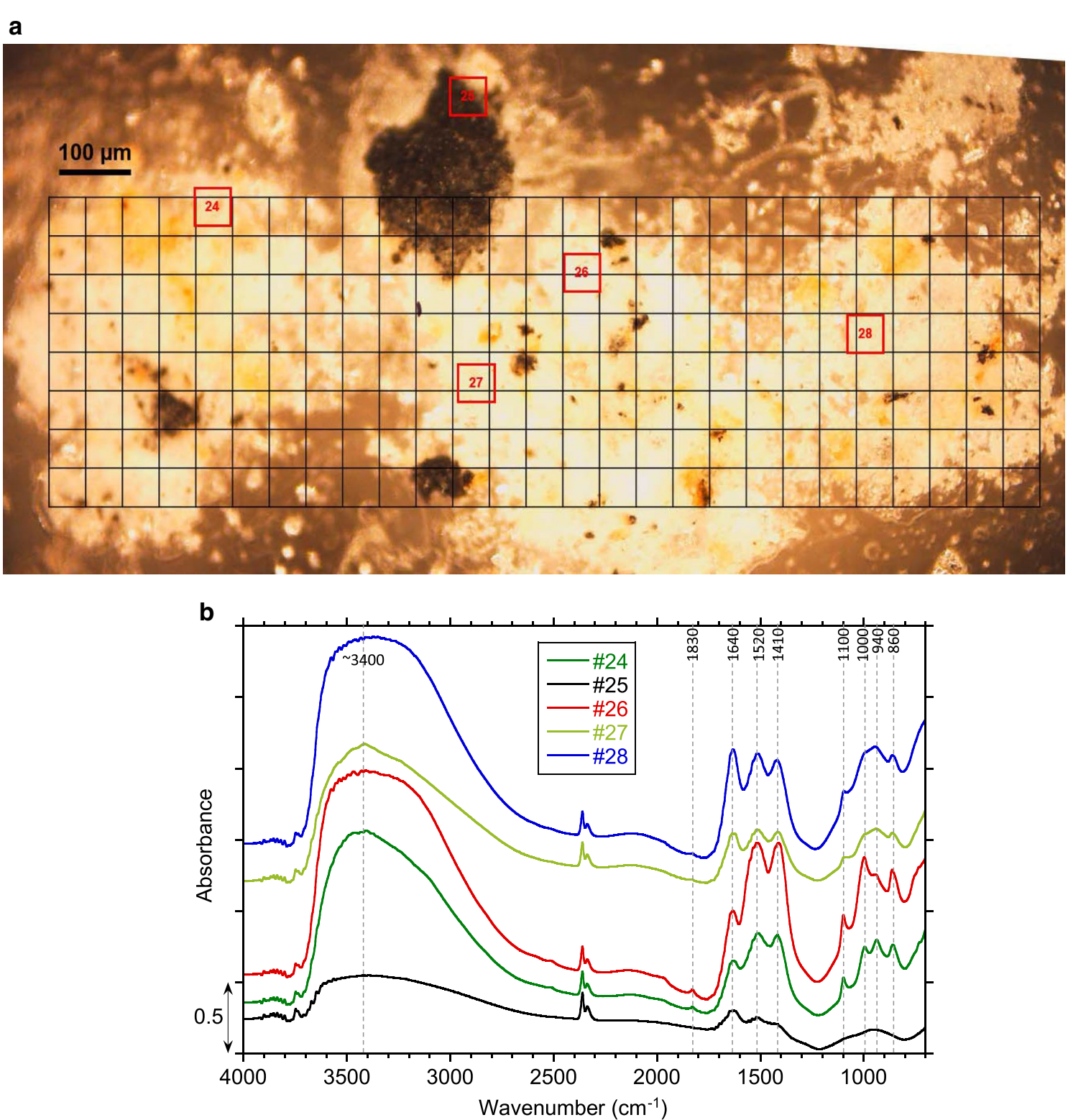

Fig. 9 a Optical microscopy image of the carbonaceous sample from the quenched product. $\mathbf{b}$ IR spectral signatures obtained from the red squares (\#24, 26-28 are from white materials and \#25 is from black material). Possible peak assignments with references (Socrates 2004) are shown in Table 1

$\ln Y=-1.78 \mathrm{X} n+6.15\left(R^{2}=0.99\right) ;$ with sabot,

$\ln Y=-1.49 \mathrm{X} n+5.60\left(R^{2}=0.99\right) ;$ without sabot.

Therefore, these linear relations imply a stepwise cyclization in which larger PAHs are formed from their smaller homologues (e.g., following the pathways for the pyrene series and the fluoranthene series proposed by Naraoka et al. 2000).

\section{Inorganic ions and elements extracted from solid carbonaceous product}

The most abundant inorganic ions from the waterextractable fractions were $\mathrm{Cl}^{-}$and $\mathrm{K}^{+}$derived from the KTB explosive and RK ignition charge components (Additional file 1: Figure S1). The other significant ions were shown to be nitrates $\left(\mathrm{NO}_{2}^{-}, \mathrm{NO}_{3}^{-}\right)$, halogens 
Table 1 Tentative peak assignments for the IR and Raman spectra based on Socrates (2004)

\begin{tabular}{|c|c|}
\hline Wavenumber/cm ${ }^{-1}$ & Functional groups \\
\hline \multicolumn{2}{|l|}{$\mathbb{R}$} \\
\hline$\sim 3400$ & $\mathrm{O}-\mathrm{H}, \mathrm{N}-\mathrm{H}$ \\
\hline $1830^{*}$ & NOX $(X=$ halogen $)$, carbonate \\
\hline $1640^{* *}$ & $\mathrm{H}_{2} \mathrm{O}, \mathrm{C}=\mathrm{C}, \mathrm{C}=\mathrm{O}$ (amide $\mathrm{I}$ ) \\
\hline $1520-10^{* *}$ & $\mathrm{C}=\mathrm{C}, \mathrm{NH}_{3}{ }^{+}, \mathrm{N}-\mathrm{H}$ (amide II) \\
\hline $1420-10^{* *}$ & $\begin{array}{l}\mathrm{CO}_{2}^{-}, \mathrm{NH}_{4}{ }^{+}, \mathrm{NO}_{3}{ }^{-}, \mathrm{C}-\mathrm{N} \text { (amide III), } \mathrm{CO}_{3}{ }^{2-} \text { (car- } \\
\text { bonate) }\end{array}$ \\
\hline $1100^{*}$ & $\mathrm{C}-\mathrm{O}, \mathrm{S}=\mathrm{O}$ \\
\hline $1000^{*}$ & $\mathrm{~S}=\mathrm{O}$ \\
\hline $940^{* *}$ & $\mathrm{~N}-\mathrm{O}$ \\
\hline $860^{*}$ & $\mathrm{NO}_{3}{ }^{-}$, carbonate \\
\hline \multicolumn{2}{|l|}{ Raman } \\
\hline 123 & Unknown \\
\hline $157-167$ & Carbonate \\
\hline 202 & Carbonate \\
\hline 235 & Unknown \\
\hline 278 & $\mathrm{C}-\mathrm{Cl}$, aromatic, carbonate \\
\hline $553-573$ & $\mathrm{C}-\mathrm{Cl}$, aromatic, amide, $\mathrm{C}=\mathrm{O}, \mathrm{C}-\mathrm{S}$ \\
\hline 726 & $\mathrm{C}-\mathrm{Cl}$, aromatic, amide, $\mathrm{C}-\mathrm{S}$, carbonate \\
\hline 1095 & $\mathrm{NO}_{3}{ }^{-}$, aromatic, $\mathrm{C}-\mathrm{O}, \mathrm{C}-\mathrm{N}, \mathrm{S}=\mathrm{O}$, carbonate \\
\hline $1475-1490$ & $\mathrm{NH}_{3}{ }^{+}$, aromatic, pyrrole, carbonate \\
\hline 1729 & $C=O$ \\
\hline
\end{tabular}

The IR peaks with * are distributed in the right area, and the peaks with ** are distributed in the IR map (Fig. 10). Since IR spectroscopy is bulk analysis and it does not detect trace components. Although aliphatic $\mathrm{C}-\mathrm{H}$ peaks were not detected by IR, aromatic species may exist (1640 and $1520-10 \mathrm{~cm}^{-1}$ could be aromatic $\mathrm{C}=\mathrm{C}$ )

$\left(\mathrm{Br}^{-}, \mathrm{F}^{-}\right)$, organic acids (acetic acid, formic acid), sulfate $\left(\mathrm{SO}_{4}{ }^{2-}\right)$, phosphate $\left(\mathrm{PO}_{4}{ }^{3-}\right)$ and ammonium $\left(\mathrm{NH}_{4}{ }^{+}\right)$by ion chromatography (IC). Sodium (Na), aluminum (Al), magnesium $(\mathrm{Mg})$, titanium $(\mathrm{Ti})$ and other elements were also observed in the solid carbonaceous product by ICPMS. Figure 8 presents the surface imaging analysis of the solid carbonaceous product observed by $\mu \mathrm{XRF}$, implying heterogeneous precipitation of solid products after the reaction of the KTB and RK explosives and the subsequent quenching effect.

\section{IR and Raman spectra}

The IR spectra were obtained at $>10$ different positions on the carbonaceous product sample. Figure 9a shows representative IR spectra from several spots in the region of interest (Fig. 9b). Although the peak positions are mostly common, the peak intensity ratios vary substantially. Three peaks are commonly observed at $\sim 1640, \sim 1515$, and $\sim 1415 \mathrm{~cm}^{-1}$. There are fine peaks at 1100, 1000, 940, and $860 \mathrm{~cm}^{-1}$. The possible peak assignments based on
Socrates (2004) are shown in Table 1. The spectra from some spots show a peak at $3417 \mathrm{~cm}^{-1}$ due to $\mathrm{N}-\mathrm{H}$, in addition to a broad $\mathrm{O}-\mathrm{H}$ band at $\sim 3400 \mathrm{~cm}^{-1}$, which is mostly due to adsorbed water, indicating that the sample is hydrophilic.

Mapping analysis in a $1350 \mu \mathrm{m} \times 400 \mu \mathrm{m}$ region shows heterogeneity at the $\sim 100 \mu \mathrm{m}$ scale-there are two groups of IR absorptions (Fig. 10). One is distributed mainly in the right area and includes bands at 860, 1000, 1100 , and $1830 \mathrm{~cm}^{-1}$. The other is distributed in three regions: left, middle, and right, and includes the bands at $940,1410,1520$, and $1640 \mathrm{~cm}^{-1}$. The black and white materials are indicated by the optical microscopic image (Fig. 9a). The black materials show less-intense IR signals compared to the white materials (Figs. $9 \mathrm{~b}$ and 10). For the interpretation of the $1640 \mathrm{~cm}^{-1}$ band implying absorbed water, we note that the amount of "hydrophilic chemical species" was detected as shown in Additional file 1: Figure S1.

The Raman spectra obtained from the carbonaceous product sample are characterized by an intense peak at $1095 \mathrm{~cm}^{-1}$ with weaker peaks mostly below $750 \mathrm{~cm}^{-1}$ (Fig. 11, Table 1). The Raman features from the black materials are mostly common with those of the white materials-although some peaks were slightly shifted and weaker than the corresponding peaks from the white materials. Considering that the IR features from the black materials are also weaker than those of white materials, the black materials could be IR and Raman inactive.

Considering the IR and Raman characteristics, the carbonaceous product sample (the white materials) likely contains nitrates, ammonium/amine salts, carbonates, and sulfur oxyanions. Aromatic compounds, amides and halides might also be present. Notably, these characteristics are not definitive, and further analyses are required to identify these compounds. To obtain the accurate evaluation of the sample profile, we need multi-technical approach including the nondestructive analysis (e.g., IR and Raman), destructive analysis (e.g., GC/MS), and comprehensive working flow (e.g., Uesugi et al. 2014, 2019).

\section{Summary and perspectives}

1. An energetic reaction involving a physicochemical explosive shock will vigorously activate of chemical substances, resulting in the abiotic synthesis of various gases and solid materials after the eventual quenching process. The KTB- and RK-based explosives produce carbonaceous debris containing various labile and refractory organic materials that do not undergo thermal degradation, and the retrieved 

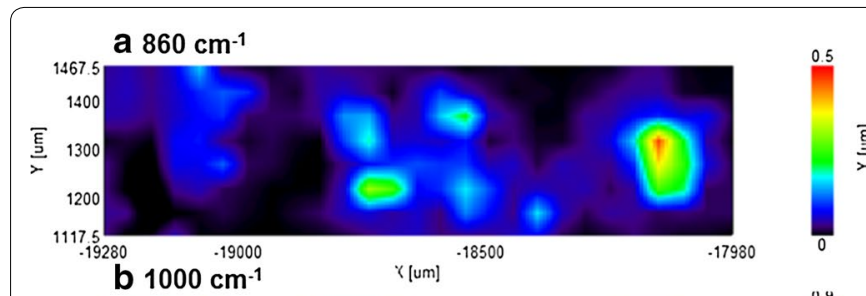

\section{e $940 \mathrm{~cm}^{-1}$}

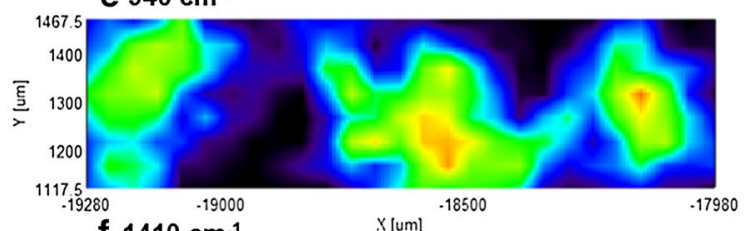

f $1410 \mathrm{~cm}^{-1}$

X Yum]
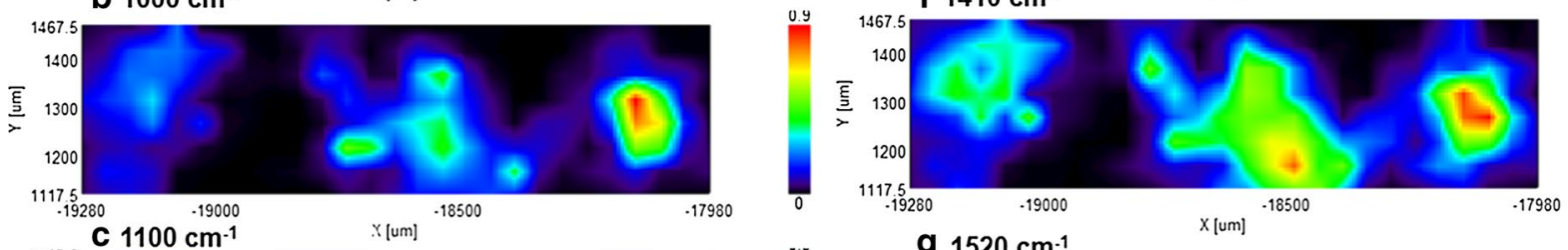

g $1520 \mathrm{~cm}^{-1}$
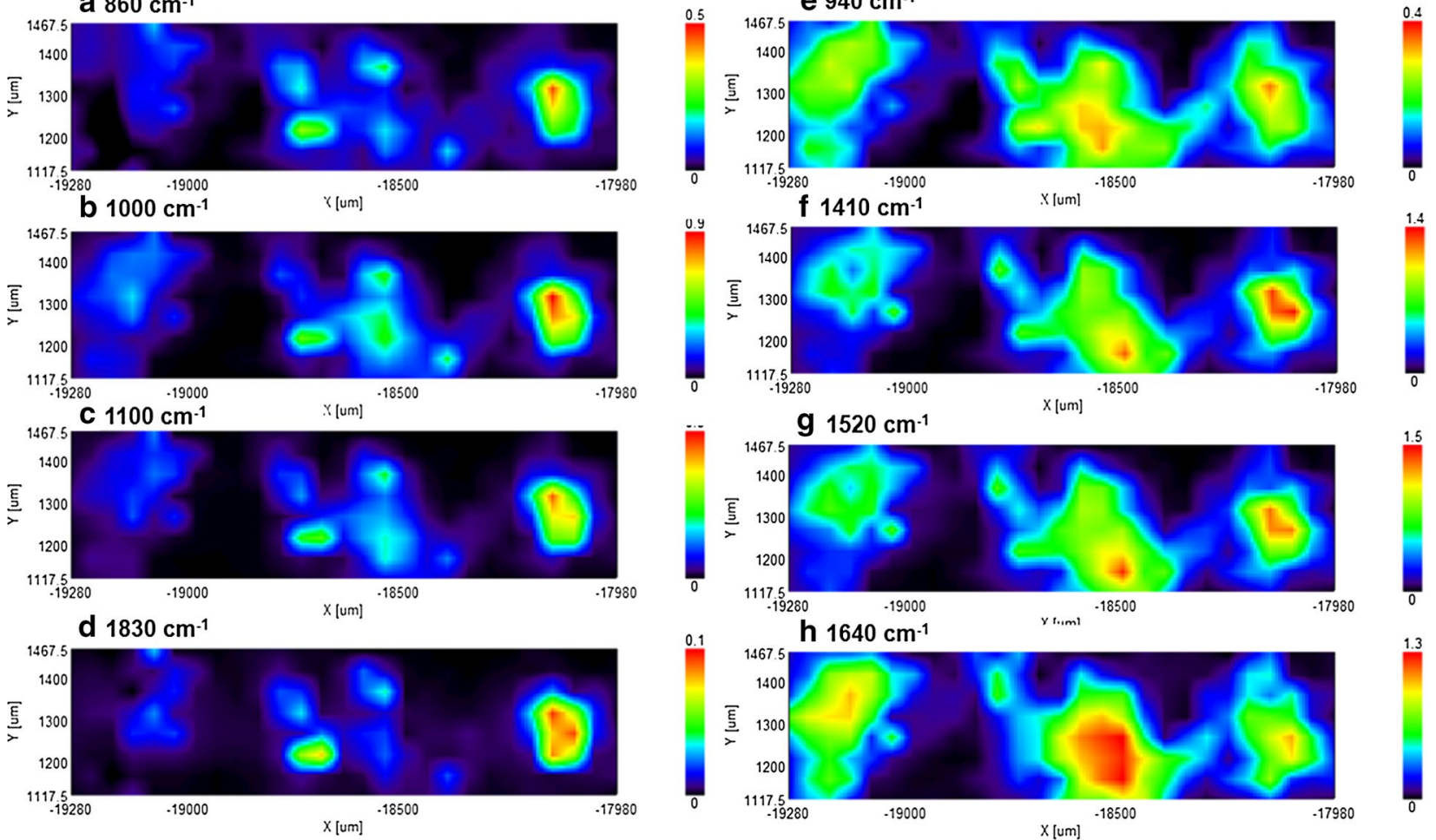

Fig. 10 IR peak intensity maps at a $860 \mathrm{~cm}^{-1}$ with baseline between 780 and $1060 \mathrm{~cm}^{-1}, \mathbf{b} \sim 1000 \mathrm{~cm}^{-1}$ with baseline between 780 and $1060 \mathrm{~cm}^{-1}$, c $1100 \mathrm{~cm}^{-1}$ with baseline between 1060 and $1140 \mathrm{~cm}^{-1}$, d $1830 \mathrm{~cm}^{-1}$ with baseline between 1780 and $1860 \mathrm{~cm}^{-1}$, e $940 \mathrm{~cm}^{-1}$ with baseline between 780 and $1060 \mathrm{~cm}^{-1}, \mathbf{f} \sim 1410 \mathrm{~cm}^{-1}$ with baseline between 1250 and $1750 \mathrm{~cm}^{-1}, \mathbf{g} \sim 1520 \mathrm{~cm}^{-1}$ with baseline between 1250 and $1750 \mathrm{~cm}^{-1}$, and $\mathbf{h} \sim 1640 \mathrm{~cm}^{-1}$ with baseline between 1250 and $1750 \mathrm{~cm}^{-1}$. IR imaging on Fig. 10 is corresponding to the region of interest in Fig. 9

sample quality is guaranteed by the closed explosion system (Sawada et al. 2017).

2. Practically, we are expecting the nominal scenario (i.e., substantial pristine grain samples from Ryugu without contamination: Tachibana et al. 2014) and also preparing the case for off-nominal scenario (i.e., minimum pristine grain samples with potential artifact materials). We reported a chemical assessment prior to the real sample process after the arrival of Hayabusa2 spacecraft and a feedback to future sample return missions (Chan et al. 2020).
3. Quality control for the sample process, including in ground-based procedures, is an important issue for sample return missions. The ESCuC (the Extraterrestrial Sample Curation Center) in the ISAS/JAXA facility (Yada et al. 2014; Uesugi et al. 2019) was assessed by an interlaboratory evaluation, and Sugahara et al. (2018) reported an assessment of the clean room at ISAS/JAXA, which is intended to be used in the processing Hayabusa2 samples (cf. assessment on the OSIRIS-REx mission; Dworkin et al. 2017). 


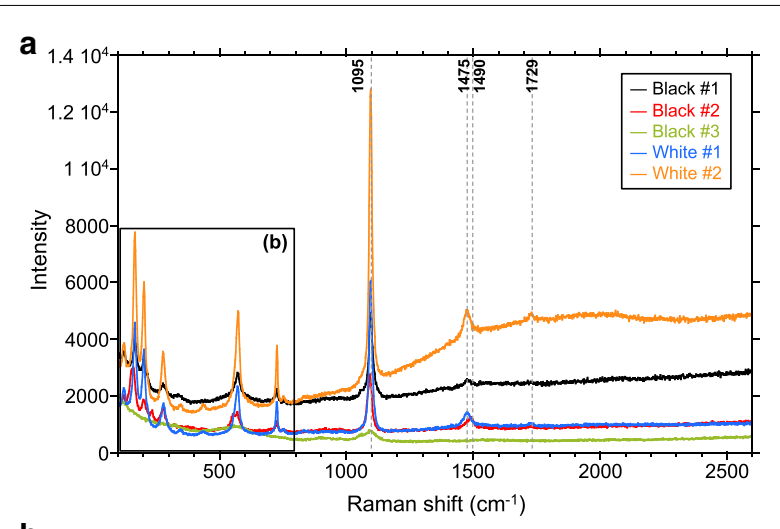

b

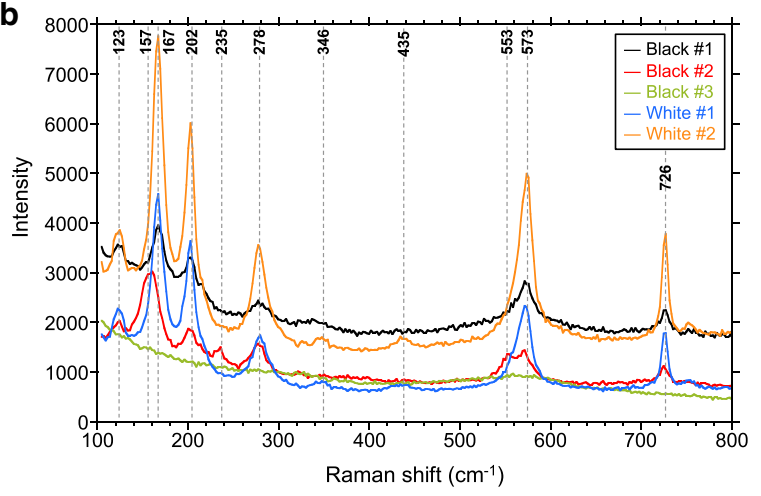

Fig. 11 Raman spectra of the carbonaceous sample from the quenched product. "Black" indicates the spectra obtained from the black materials, and "white" indicates the spectra obtained from the white materials

Along with those quality controls above, the analytical flow of pristine samples (e.g., element profiles, chemical composition, mineralogy, isotopic signatures, organic molecules, and physical properties) definitely requires a seamless process to obtain precise and native information for the asteroid Ryugu.

\section{Supplementary information}

Supplementary information accompanies this paper at https://doi. org/10.1186/s40623-020-01217-y.

Additional file 1: Figure S1. Profiles of cations and anions obtained from the quenched 80 carbonaceous product ( $\mathrm{w} /$ and $\mathrm{w} / \mathrm{o}$ the sabot; sampled from $32.4 \mathrm{mg}$ and $31.3 \mathrm{mg}$ of material, respectively) analyzed by ion chromatography. Abbreviation: 2A2M, 2-amino-2-methyl-1-propanol; DMA, dimethylamine. Figure S2. Profiles of the major elements obtained from the quenched carbonaceous product ( $w /$ and $w / o$ the sabot) analyzed by inductively coupled plasma-mass spectrometry.

\section{Abbreviations}

C-type: Carbonaceous-type; VOCs: Volatile organic compounds; PAH: Polycyclic aromatic hydrocarbons; GC: Gas chromatography; SPME: Solid-phase microextraction; TDS: Thermal desorption system; GC/MS: GC coupled with mass spectrometry; TIC: Total ion chromatogram; EIC: Extracted ion chromatogram; ICP-MS: Inductively coupled plasma-mass spectrometry; $\mu$ XRF: Micro $X$-ray fluorescence; FT-IR: Fourier transform infrared; ESCUC: The Extraterrestrial Sample Curation Center; OSIRIS-REx: Origins, Spectral Interpretation, Resource Identification, Security, Regolith Explorer.

\section{Acknowledgements}

We express our sincere thanks to the associate editor Dr. Takaaki Noguchi (Kyushu Univ.) and two anonymous reviewers for the valuable comments, which helped to improve the earlier version of the manuscript. The experiments with explosives were permitted by the Institute of Space and Astronautical Science (ISAS). We thank Akira Fujiwara, Sunao Hasegawa and Masanao Abe of ISAS/JAXA, Kazuyoshi Takayama and Koichi Okano of Tohoku University for contributing the original design and development of the Hayabusa projector sub-system. The Hayabusa2 project team is acknowledged for supervising assessment experiments of the Hayabusa2 projector. We appreciate the Space Plasma Laboratories at ISAS, JAXA, for their support in the development of the Hayabusa2 sampler as a collaborative research program. We also thank Renesas Semiconductor Manufacturing Co. Ltd. and Toshiba Nanoanalysis Corporation for their help with the assessments. Preliminary reports based on this paper were presented at Hayabusa 2015 (3rd symposium of Solar System Materials) and the Solar System Symposium in Sapporo, 2020.

\section{Authors' contributions}

YT conducted the experiments, interpreted the data, and finalized the manuscript. KY conducted the experiments for volatile gas analyses and interpreted the data. CO, KS and RO conducted the experiments and participated in upgrading the projector sub-system and in the analytical assessments. KK, YK, MI and TS performed nondestructive analyses by FT-IR and Raman spectroscopy. HY developed the Hayabusa projector sub-system while HS and ST led the upgrading activity of the Hayabusa2 projector system, according to the assessment results with $\mathrm{YT}, \mathrm{RO}, \mathrm{CO}$, and $\mathrm{KS}$. All authors contributed to the manuscript and approved the final version of the content. All authors read and approved the final manuscript.

\section{Funding}

This work was supported by a Grant-in-Aid for Scientific Research on Innovative Areas (Research Project on Evolution of Molecules in Space; YT, No. 25108006) by project leader Prof. Akira Kouchi (Hokkaido Univ.) from the Japan Society for the Promotion of Science (JSPS) and in part by a JSPS grant (No. 19H00712, ST; No. 16H04083, YT; No. JP17H06458, YK\&TS).

\section{Availability of data and materials}

The movie of a shooting verification using an identical bullet, i.e., equivalent product manufactured at the same time as the flight model, is provided in the website. http://www.hayabusa2.jaxa.jp/en/topics/20190214e_Experiment/. Please contact the authors for other data requests.

\section{Competing interests}

The authors declare that they have no competing interests regarding this document.

\section{Author details}

${ }^{1}$ Biogeochemistry Research Center (BGC), Japan Agency for Marine-Earth Science and Technology (JAMSTEC), Natsushima, Yokosuka 237-0061, Japan. ${ }^{2}$ Department of Environmental Chemistry and Engineering, Tokyo Institute of Technology, Yokohama, Kanagawa 226-8503, Japan. ${ }^{3}$ Department of Planetology, Kobe University, 1-1, Rokkodai-cho, Kobe 657-8501, Japan. ${ }^{4}$ Institute of Space and Astronautical Science (ISAS), Japan Aerospace Exploration Agency (JAXA), 3-1-1 Yoshinodai, Sagamihara, Kanagawa 252-5210, Japan. ${ }^{5}$ Department of Earth and Planetary Science, Kyushu University, 744 Motooka, Nishi-ku, Fukuoka 819-0395, Japan. ${ }^{6}$ Graduate School of Engineering Science, Yokohama National University, 79-5 Tokiwadai, Hodogaya-ku, Yokohama 240-8501, Japan. ${ }^{7}$ Super-cutting-edge Grand and Advanced Research (SUGAR) Program, Japan Agency for Marine-Earth Science and Technology (JAMSTEC), Natsushima, Yokosuka 237-0061, Japan. ${ }^{8}$ Department of Earth and Planetary Science, UTokyo Organization for Planetary and Space Science (UTOPS), University of Tokyo, 7-3-1 Hongo, Tokyo 113-0033, Japan. 


\section{Appendix}<smiles>Cc1ccccc1</smiles>
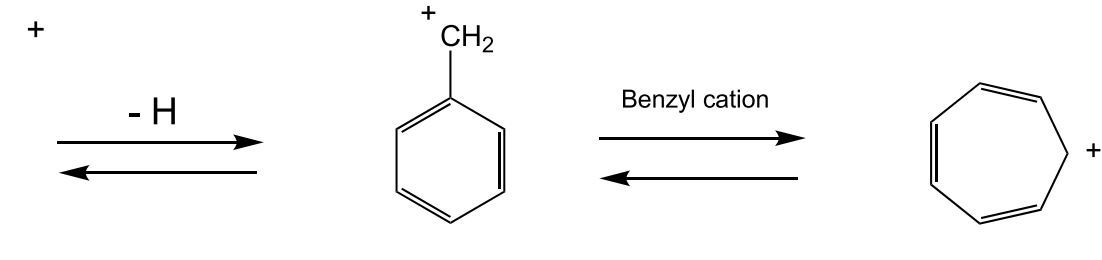

$m / z=92$

$m / z=91$

$m / z=91$

Toluene to benzyl cation isomerism via $m / z=91$ and

$m / z=92$.

Received: 26 March 2020 Accepted: 20 June 2020

Published online: 11 July 2020

\section{References}

Arthur CL, Pawliszyn J (1990) Solid phase microextraction with thermal desorption using fused silica optical fibers. Anal Chem 62:2145-2148. https:// doi.org/10.1021/ac00218a019

Chan QHS, Stroud R, Martins Z, Yabuta H (2020) Concerns of organic contamination for sample return space missions. Space Sci Rev 216:56. https:// doi.org/10.1007/s11214-020-00678-7

Chen P, Huang F, Yun S (2003) Characterization of the condensed carbon in detonation soot. Carbon 41:2093-2099. https://doi.org/10.1016/S0008 $-6223(03) 00229-X$

Dworkin JP, Adelman LA, Ajluni T, Andronikov AV, Aponte JC, Bartels AE, Beshore E, Bierhaus EB, Brucato JR, Bryan BH, Burton AS, Callahan MP, Castro-Wallace SL, Clark BC, Clemett SJ, Connolly HC, Cutlip WE, Daly SM, Elliott VE, Elsila JE, Enos HL, Everett DF, Franchi IA, Glavin DP, Graham HV, Hendershot JE, Harris JW, Hill SL, Hildebrand AR, Jayne GO, Jenkens RW, Johnson KS, Kirsch JS, Lauretta DS, Lewis AS, Loiacono JJ, Lorentson CC, Marshall JR, Martin MG, Matthias LL, McLain HL, Messenger SR, Mink RG, Moore JL, Nakamura-Messenger K, Nuth JA, Owens CV, Parish CL, Perkins BD, Pryzby MS, Reigle CA, Righter K, Rizk B, Russell JF, Sandford SA, Schepis JP, Songer J, Sovinski MF, Stahl SE, Thomas-Keprta K, Vellinga JM, Walker MS (2017) OSIRIS-REx Contamination control strategy and implementation. Space Sci Rev 214:19. https://doi.org/10.1007/s1121 4-017-0439-4

Fujiwara A, Yano H (2005) The asteroidal surface sampling system onboard the Hayabusa spacecraft. Aeronaut Space Sci Japan 53:264-271. https://doi. org/10.14822/kjsass.53.620_264

García RA, Morales V, Martín S, Vilches E, Toledano A (2014) Volatile organic compounds analysis in breath air in healthy volunteers and patients suffering epidermoid laryngeal carcinomas. Chromatographia 77:501-509. https://doi.org/10.1007/s10337-013-2611-7

Greiner NR, Phillips D, Johnson J, Volk F (1988) Diamonds in detonation soot. Nature 333:440-442. https://doi.org/10.1038/333440a0

Ito M, Uesugi M, Naraoka H, Yabuta H, Kitajima F, Mita H, Takano Y, Karouji Y, Yada T, Ishibashi Y (2014) H, C, and N isotopic compositions of Hayabusa category 3 organic samples. Earth Planets Space 66:91. https://doi. org/10.1186/1880-5981-66-91

Kebukawa Y, Zolensky ME, I to M, Ogawa NO, Takano Y, Ohkouchi N, Nakato A, Suga H, Takeichi Y, Takahashi Y, Kobayashi K (2020) Primordial organic matter in the xenolithic clast in the Zag $\mathrm{H}$ chondrite: possible relation to D/P asteroids. Geochim Cosmochim Acta 271:61-77. https://doi. org/10.1016/j.gca.2019.12.012

Kiryu K, Kebukawa Y, Igisu M, Shibuya T, Kobayashi K (2019) Kinetic estimation of the thermal history of organic matter in chondrites using Raman Spectroscopy, 82nd Annual Meeting of The Meteoritical Society. Abstract\#6250
Kitajima F, Uesugi M, Karouji Y, Ishibashi Y, Yada T, Naraoka H, Abe M, Fujimura A, Ito M, Yabuta H, Mita H, Takano Y, Okada T (2015) A micro-Raman and infrared study of the several Hayabusa category 3 (organic) particles. Earth Planets Space 67:20. https://doi.org/10.1186/s40623-015-0182-6

Kitazato K, Milliken RE, Iwata T, Abe M, Ohtake M, Matsuura S, Arai T, Nakauchi Y, Nakamura T, Matsuoka M, Senshu H, Hirata N, Hiroi T, Pilorget C, Brunetto R, Poulet F, Riu L, Bibring J-P, Takir D, Domingue DL, Vilas F, Barucci MA, Perna D, Palomba E, Galiano A, Tsumura K, Osawa T, Komatsu M, Nakato A, Arai T, Takato N, Matsunaga T, Takagi Y, Matsumoto K, Kouyama T, Yokota Y, Tatsumi E, Sakatani N, Yamamoto Y, Okada T, Sugita S, Honda R, Morota T, Kameda S, Sawada H, Honda C, Yamada M, Suzuki H, Yoshioka K, Hayakawa M, Ogawa K, Cho Y, Shirai K, Shimaki Y, Hirata N, Yamaguchi A, Ogawa N, Terui F, Yamaguchi T, Takei Y, Saiki T, Nakazawa S, Tanaka S, Yoshikawa M, Watanabe S, Tsuda Y (2019) The surface composition of asteroid 162173 Ryugu from Hayabusa2 near-infrared spectroscopy. Science 364:272-275. https://doi.org/10.1126/science.aav7432

Kuznetsov VL, Chuvilin AL, Butenko YV, Mal'kov IY, Titov VM (1994) Onion-like carbon from ultra-disperse diamond. Chem Phys Lett 222:343-348. https ://doi.org/10.1016/0009-2614(94)87072-1

Ligor T, Szeliga J, Jackowski M, Buszewski B (2007) Preliminary study of volatile organic compounds from breath and stomach tissue by means of solid phase microextraction and gas chromatography/mass spectrometry. J Breath Res 1:016001. https://doi.org/10.1088/1752-7155/1/1/016001

Mansurov Z (2005) Soot formation in combustion processes (review). Combust Explos Shock Waves 41:727-744. https://doi.org/10.1007/s1057 3-005-0083-2

Mimura K (1995) Synthesis of polycyclic aromatic hydrocarbons from benzene by impact shock: its reaction mechanism and cosmochemical significance. Geochim Cosmochim Acta 59:579-591. https://doi. org/10.1016/0016-7037(95)00326-U

Naraoka H, Shimoyama A, Harada K (2000) Isotopic evidence from an Antarctic carbonaceous chondrite for two reaction pathways of extraterrestrial PAH formation. Earth Planet Sci Lett 184:1-7. https://doi.org/10.1016/S0012 $-821 \times(00) 00316-2$

Naraoka H, Aoki D, Fukushima K, Uesugi M, Ito M, Kitajima F, Mita H, Yabuta H, Takano Y, Yada T, Ishibashi Y, Karouji Y, Okada T, Abe M (2015) ToF-SIMS analysis of carbonaceous particles in the sample catcher of the Hayabusa spacecraft. Earth Planets Space 67:67. https://doi.org/10.1186/s4062 3-015-0224-0

Oba Y, Takano Y, Naraoka H, Watanabe N, Kouchi A (2019) Nucleobase synthesis in interstellar ices. Nature Commun. https://doi.org/10.1038/s4146 7-019-12404-1

Okazaki R, Sawada H, Yamanouchi S, Tachibana S, Miura Y, Sakamoto K, Takano Y, Abe M, Itoh S, Yamada K, Yabuta H, Okamoto C, Yano H, Noguchi T, Nakamura T, Nagao K (2017) Hayabusa2 sample container: metal-seal system for vacuum encapsulation of returned samples. Space Sci Rev 208:107-124. https://doi.org/10.1007/s11214-016-0289-5

Pearson VK, Sephton M, Gilmour I (2006) Molecular and isotopic indicators of alteration in CR chondrites. Meteorit Planet Sci 41:1291-1303. https://doi. org/10.1111/j.1945-5100.2006.tb00522.x 
Radke M, Willsch H, Leythaeuser D, Teichmüller M (1982) Aromatic components of coal: relation of distribution pattern to rank. Geochim Cosmochim Acta 46:1831-1848. https://doi.org/10.1016/0016-7037(82)90122-3

Sawada H, Okazaki R, Tachibana S, Sakamoto K, Takano Y, Okamoto C, Yano H, Miura Y, Abe M, Hasegawa S, Noguchi T, Hayabusa2 sampler team (2017) Hayabusa2 Sampler: collection of asteroidal surface material. Space Sci Rev 208:81-106. https://doi.org/10.1007/s11214-017-0338-8

Socrates G (2004) Infrared and Raman characteristic group frequencies: tables and charts. Wiley, Hoboken

Sugahara H, Takano Y, Karouji Y, Yada T, Ohkouchi N, Abe M, Hayabusa2 Project Team (2018) (2018) Amino acids on witness coupons collected from the ISAS/JAXA curation facility for the assessment and quality control of the Hayabusa2 sampling procedures. Earth Planets Space 70:194. https://doi. org/10.1186/s40623-018-0965-7

Sugita S, Honda R, Morota T, Kameda S, Sawada H, Tatsumi E, Yamada M, Honda C, Yokota Y, Kouyama T, Sakatani N, Ogawa K, Suzuki H, Okada T, Namiki N, Tanaka S, lijima Y, Yoshioka K, Hayakawa M, Cho Y, Matsuoka M, Hirata N, Hirata N, Miyamoto H, Domingue D, Hirabayashi M, Nakamura T, Hiroi T, Michikami T, Michel P, Ballouz R-L, Barnouin OS, Ernst CM, Schröder SE, Kikuchi H, Hemmi R, Komatsu G, Fukuhara T, Taguchi M, Arai T, Senshu H, Demura H, Ogawa Y, Shimaki Y, Sekiguchi T, Müller TG, Hagermann A, Mizuno T, Noda H, Matsumoto K, Yamada R, Ishihara Y, Ikeda H, Araki H, Yamamoto K, Abe S, Yoshida F, Higuchi A, Sasaki S, Oshigami S, Tsuruta S, Asari K, Tazawa S, Shizugami M, Kimura J, Otsubo T, Yabuta H, Hasegawa S, Ishiguro M, Tachibana S, Palmer E, Gaskell R, Le Corre L, Jaumann R, Otto K, Schmitz N, Abell PA, Barucci MA, Zolensky ME, Vilas F, Thuillet F, Sugimoto C, Takaki N, Suzuki Y, Kamiyoshihara H, Okada M, Nagata K, Fujimoto M, Yoshikawa M, Yamamoto Y, Shirai K, Noguchi R, Ogawa N, Terui F, Kikuchi S, Yamaguchi T, Oki Y, Takao Y, Takeuchi H, Ono G, Mimasu Y, Yoshikawa K, Takahashi T, Takei Y, Fujii A, Hirose C, Nakazawa S, Hosoda S, Mori O, Shimada T, Soldini S, Iwata T, Abe M, Yano H, Tsukizaki R, Ozaki M, Nishiyama K, Saiki T, Watanabe S, Tsuda Y (2019) The geomorphology, color, and thermal properties of Ryugu: implications for parent-body processes. Science 364:eaaw0422

Szmigielski R, Cieslak M, Rudziński KJ, Maciejewska B (2012) Identification of volatiles from Pinus silvestris attractive for Monochamus galloprovincialis using a SPME-GC/MS platform. Environ Sci Pollut Res 19:2860-2869. https ://doi.org/10.1007/s11356-012-0792-5

Tachibana S, Abe M, Arakawa M, Fujimoto M, lijima Y, Ishiguro M, Kitazato K, Kobayashi N, Namiki N, Okada T, Okazaki R, Sawada H, Sugita S, Takano Y, Tanaka S, Watanabe S, Yoshikawa M, Kuninaka H, Hayabusa2 project team (2014) Hayabusa2: scientific importance of samples returned from near-Earth C-type asteroid 1999 JU3. Geochem J 48:571-587. https://doi. org/10.2343/geochemj.2.0350

Takano Y, Chikaraishi Y, Ohkouchi N (2015) Isolation of underivatized amino acids by ion-pair high performance liquid chromatography for precise measurement of nitrogen isotopic composition of amino acids: development of comprehensive LC x GC/C/IRMS method. Int J Mass Spectrom 379:16-25. https://doi.org/10.1016/j.ijms.2014.11.012

Titov, V., Anisichkin, V. and Mal'kov, I. Y. (1989) Synthesis of ultrafine diamonds in detonation waves. Papers 9th Symposium (International) on Explosion, pp 175-183

Tuckey NPL, Day JR, Miller MR (2013) Determination of volatile compounds in New Zealand Greenshell ${ }^{\mathrm{TM}}$ mussels (Perna canaliculus) during chilled storage using solid phase microextraction gas chromatography-mass spectrometry. Food Chem 136:218-223. https://doi.org/10.1016/j.foodc hem.2012.07.118

Uesugi M, Naraoka H, Ito M, Yabuta H, Kitajima F, Takano Y, Mita H, Ohnishi I, Kebukawa Y, Yada T, Karouji Y, Ishibashi Y, Okada T, Abe M (2014) Sequential analysis of carbonaceous materials in Hayabusa-returned samples for the determination of their origin. Earth Planets Space 66:102. https://doi. org/10.1186/1880-5981-66-102

Uesugi M, Ito M, Yabuta H, Naraoka H, Kitajima F, Takano Y, Mita H, Kebukawa Y, Nakato A, Karouji Y (2019) Further characterization of carbonaceous materials in Hayabusa-returned samples to understand their origin. Meteorit Planet Sci 54:638-666. https://doi.org/10.1111/maps.13236

Wang V-S, Lu M-Y (2009) Application of solid-phase micro extraction and gas chromatography/mass spectrometry for measuring chemicals in saliva of synthetic leather workers. J Chromatogr B 877:24-32. https://doi. org/10.1016/j.jchromb.2008.11.006
Watanabe S, Hirabayashi M, Hirata N, Hirata N, Noguchi R, Shimaki Y, Ikeda H, Tatsumi E, Yoshikawa M, Kikuchi S, Yabuta H, Nakamura T, Tachibana S, Ishihara Y, Morota T, Kitazato K, Sakatani N, Matsumoto K, Wada K, Senshu H, Honda C, Michikami T, Takeuchi H, Kouyama T, Honda R, Kameda S, Fuse T, Miyamoto H, Komatsu G, Sugita S, Okada T, Namiki N, Arakawa M, Ishiguro M, Abe M, Gaskell R, Palmer E, Barnouin OS, Michel P, French AS, McMahon JW, Scheeres DJ, Abell PA, Yamamoto Y, Tanaka S, Shirai K, Matsuoka M, Yamada M, Yokota Y, Suzuki H, Yoshioka K, Cho Y, Tanaka S, Nishikawa N, Sugiyama T, Kikuchi H, Hemmi R, Yamaguchi T, Ogawa N, Ono G, Mimasu Y, Yoshikawa K, Takahashi T, Takei Y, Fujii A, Hirose C, Iwata T, Hayakawa M, Hosoda S, Mori O, Sawada H, Shimada T, Soldini S, Yano H, Tsukizaki R, Ozaki M, lijima Y, Ogawa K, Fujimoto M, Ho T-M, Moussi A, Jaumann R, Bibring J-P, Krause C, Terui F, Saiki T, Nakazawa S, Tsuda Y (2019) Hayabusa2 arrives at the carbonaceous asteroid 162173 Ryugu-A spinning top-shaped rubble pile. Science 364:268-272. https://doi. org/10.1126/science.aav8032

Yabuta H, Uesugi M, Naraoka H, Ito M, Kilcoyne ALD, Sandford SA, Kitajima F, Mita H, Takano Y, Yada T, Karouji Y, Ishibashi Y, Okada T, Abe M (2014) Molecular compositions of Hayabusa Category 3 carbonaceous particles. Earth Planets Space 66:156. https://doi.org/10.1186/s40623-014-0156-0

Yada T, Fujimura A, Abe M, Nakamura T, Noguchi T, Okazaki R, Nagao K, Ishibashi Y, Shirai K, Zolensky ME (2014) Hayabusa-returned sample curation in the planetary material sample curation facility of JAXA. Meteorit Planet Sci 49:135-153. https://doi.org/10.1111/maps.12027

Yano, H., Hasegawa, S., Abe, M. and Fujiwara, A. (2002) Asteroidal surface sampling by the MUSES-C spacecraft. Proceedings of Asteroids, Comets, Meteors (ACM2002), ESA-SP-500, 103-106

Yano H, Kubota T, Miyamoto H, Okada T, Scheeres D, Takagi Y, Yoshida K, Abe M, Abe S, Barnouin-Jha O, Fujiwara A, Hasegawa S, Hashimoto T, Ishiguro M, Kato M, Kawaguchi J, Mukai T, Saito J, Sasaki S, Yoshikawa M (2006) Touchdown of the Hayabusa spacecraft at the Muses Sea on Itokawa. Science 312:1350-1353. https://doi.org/10.1126/science.1126164

Yuen G, Blair N, Desmarais DJ, Chang S (1984) Carbon isotope composition of low-molecular weight hydrocarbons and monocarboxylic acids from Murchison meteorite. Nature 307:252-254. https://doi.org/10.1038/307252a0

\section{Publisher's Note}

Springer Nature remains neutral with regard to jurisdictional claims in published maps and institutional affiliations.

\section{Submit your manuscript to a SpringerOpen ${ }^{\circ}$ journal and benefit from:}

- Convenient online submission

- Rigorous peer review

- Open access: articles freely available online

- High visibility within the field

- Retaining the copyright to your article

Submit your next manuscript at springeropen.com 